إدراك المهنسين الزراعيين لاور الإرشاد الزراعي التسويقي في ظل العولمة بمحافظة القليوبية

$$
\text { سعيد عباس محمد رشاد'، مصباح سالم الهوش'، رضا طحاوي طاهر طحاوي' }
$$

النسبي الكبير في الأداء من جانب العاملين بالأجهزة

$$
\text { الإرشادية. }
$$

r-أن ترتيب الأنثطة الإرشادية وفقا للمتوسط المرجح للاور

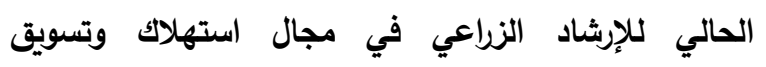

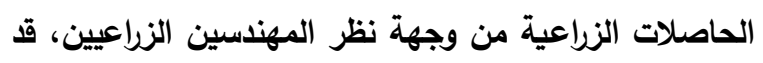

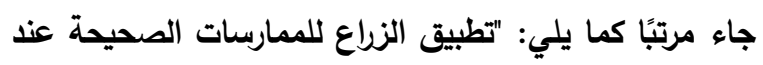

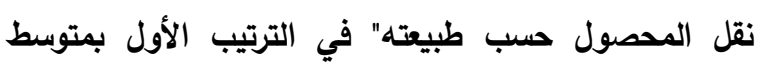

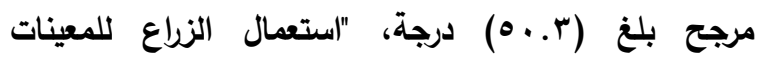

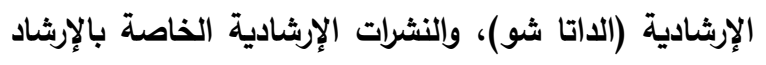

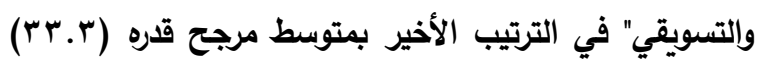

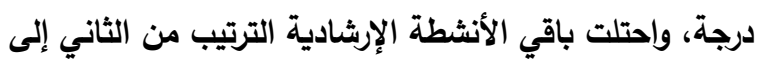
الخامس. r-أن تقسيم الاور الحالي لمجال تسويق وإستهلاك الحاصلات

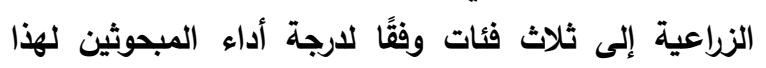

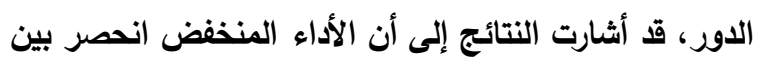

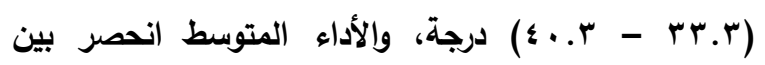

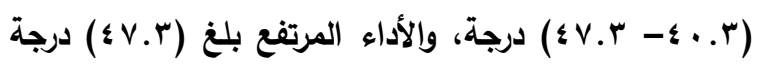
فأكثر. ع-تم وضع مقترح خطة عمل إرشادية لبرنامج تدربي يوجه

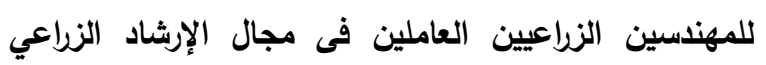
عامة، والإرشاد التسويقي خاصة، وقد رُوعي فيه أن يكون

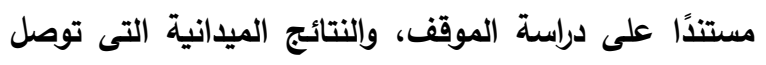

$$
\text { إليها هذا البحث. }
$$

ه-كانت أهم المشكلات التى واجهت المهندسين الزراعيين

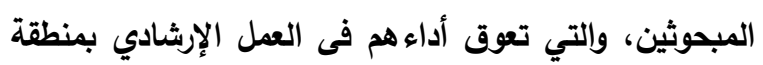

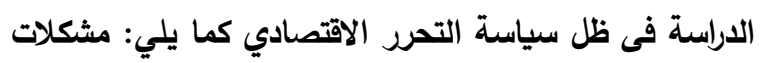

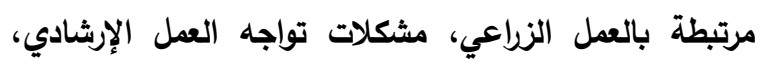

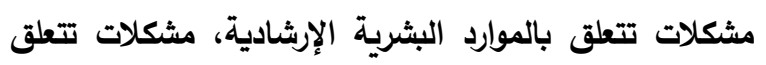

\section{الملخص العربى}

استهدف البحث بصفة رئيسية تحديد مستوى الإدراك للاور

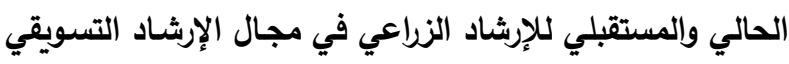

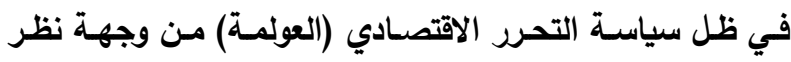

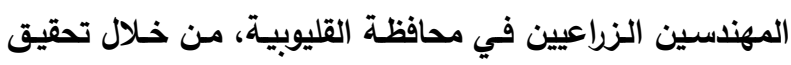

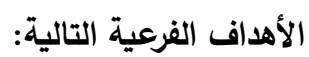
1 ـ تحديد مدي إدراك المهندسين الزراعيين لدور الإرشاد الزراعي الحالي والمستقبلي في مجال الإرشاد التسويقي.

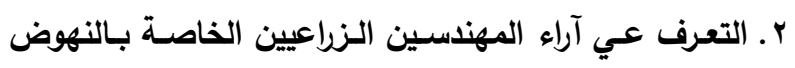

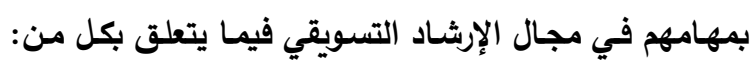

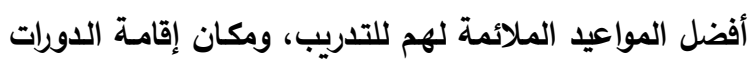
التدربيـة، والطـرق المفضـلة لهـم في التـدربب، والمـدربين القائمين بالتدريب. r. اقتراح خطة عمل لبرنـامج تدرببي لتنمية الإرشـاد التسويقي

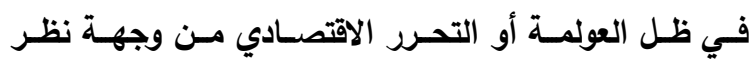
المهندين الزراعيين وفقا لصفاتهم الشخصية، والاتصالية، والاجتماعية، ومستوى إدراكهم للاور الإرشادي التسويقي.

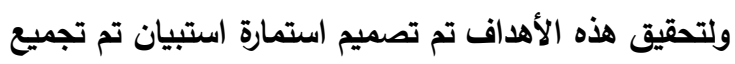
بياناتها بالمقابلة الشخصية مع عينـة من المبحوثين بلـغ قوامها

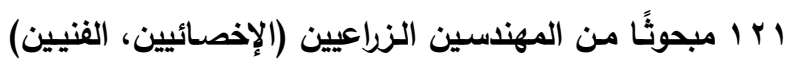

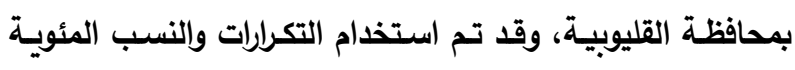
والمتوسطات لعرض البيانات وترتيب المهام المحددة للدور الذي يقوم بها المهندسين الزراعيين في مجال الإرشاد التسويقي. وتمثلت اهم النتائج فيما يلي:

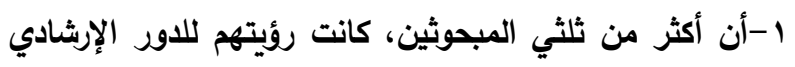

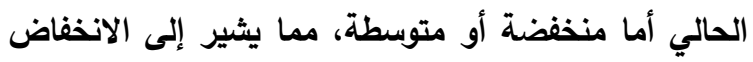

\footnotetext{
'قسم الاقتصاد الزراعي - كلية الزراعة - جامعة بنها. ب قسم الاقتصاد الزراعي - كلية الزراعة - جامعة طرابلس.

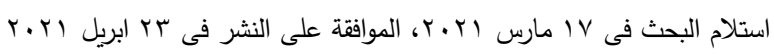




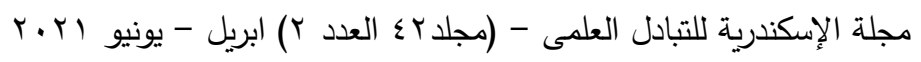

المجتمع كل ذلك يحدث في ضوء الاندماج العالمي، ومتابعة التغيرات العالمية خاصة في ظل التوجهات العالمية إلي

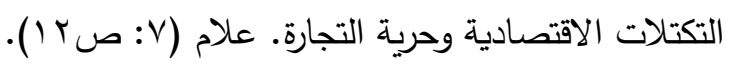
والعولمة من منظور إدارة الأنشطة التسويقية التصديرية هي عولمة النشاط المالي، والتسويقي، والإنتاجي،

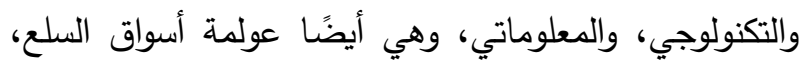
والخدمات، والمال، والتكنولوجيا، والعمالة، حيث ويت ولتعامل

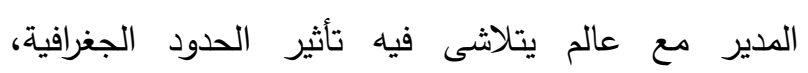
والسياسية، عالم سقطت الحواجز التجارية بين أسواقه بعد العمل باتفاقية "الجات" وما أفرزته من قيام منظمة التجارة العالمية، وتلاشت أيضًا الحواجز الفكرية، والثقافية بفعل ثورة تكنولوجيا الاتصالات والمعلومات. ريحان (7: صسباتهر (1). وللعولمة محاور متعددة، فأنت بحك الإداري، والاستثماري، وبمعايير موضوعية، مدعو لأن تحلل متغيرات سوقية عالمية، فتشتري بعض مستلزماتك من دولة أو دول

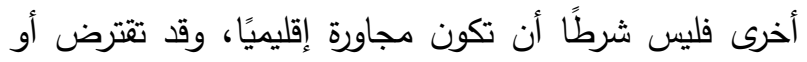
تحصل على تمويل خارجي من بنك عالمي، أو صندوق تمويل، أو من شركة أخرى خارج بلدك، وقد تتمي محفظتك المالية بشراء أسهم، أو سندات في أسواق عالمية، أو تثتري

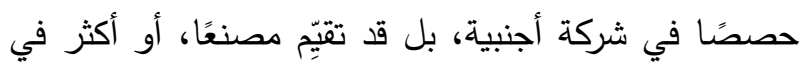
دول أخرى، كما فعل كثير من المستثمرين والمديرين اليابانيين

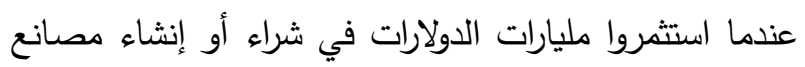
في أوروبا، وأمريكا علي سبيل المثال، وقد تستقدم عمالًا أو أولاء مديرين من جنسيات مختلفة، وثقافات متعددة، والأهم من ذلك أن تتطلع للخروج من سوقك المحلية أو الإقليمية للسوق العالمية الأوسع، حيث يتطلب الأمر أن تدرس ثقافات، وقيمًا، واتجاهات، ودوافع، ورغبات، وسلوكيات، وتقسيمات متعددة

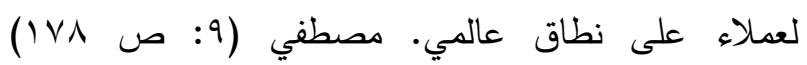
Swanson لـيس هــذا فقـط بـل يتطلـب الأمـر أن تـدرس، وتحلـل سـلوكيات منافسين تعكسها قراراتهم التي تصساغ في مقـار
بالموارد المادية، مشكلات تتعلق بالرضا الوظيفي للمهندين الزراعيين. الكلمات المفتاحية: التحرر الاقتصادي_ادراك الدور _الارشاد التسويقي

\section{المقدمة والمثكلة البحثية}

تعرف الجودة للمنتج الزراعي بشكل عام على أنها عبارة عن مزيج من المميزات والخصائص التى تعطي للمنتج الزراعي قيمة، وأهمية لاستخدامه كغذاء للإنسان، والحيوان، أو لاستخدامه في الترويج والتجميل، أو في الصناعة، وقد ركزت غالبية الجهود البحثية والإنتاجية علي تطوير الإنتاج وزيادته، من حيث الكم دون الاهتمام بالكيف وبالتالي لم تعط لإله للجودة - أي: النوعية - الاهتمام الواجب، مما أدى إلى لى حدوث فجوة كبيرة بين الإنتاج والتسويق، وتسببت تلك الك السياسات في عدم ربط الإنتاج باحتياجات السوق ومتطلباته، ومما ساعد على شيوع الأمور سالفة الذكر ، الفهم الخاطئ لدى الكثيرين لمفهوم اقتصاديات السوق والتي تعني عندهم غياب دور الدولة والتحرك بحرية والانطلاق بلا ضوابط أو روابط أو تحكم مركزي من الدولة لضبط الإيقاع وضمان الالتزام بمعايير الجودة وحماية البيئة وحماية الاقتصاد القومي، وتقرض التطورات الجارية الحاجة إلى صياغة جديدة لدور العاملين بالخدمة الإرشادية الزراعية لتحقيق الكفاءة، والجودة في تسويق الحاصلات الزراعية بالاهتمام بالمجالات الإرشادية المستحدثة أو ما يعرف بالإرشاد التسويقي، بما يتلاءم مع تحقيق الأهداف القومية في ظل العولمة وتعاظم التحديات أمام القطاع الزراعي المصري والفرص المتاحة لإدماجه في الاقتصاد العالمي. رشاد (0: ص: (1). ولقد ارتكزت سياسة التحرر الاقتصادي علي عدد من المبادئ كالثمولية سواء شمولية الاجراءات أو الحلول، كذلك شمولية كل القطاعات والمناشط الاقتصادية منها تحديث أو تجديد في قطاع أو نشاط ونترك آخر، ثم مبدأ المشاركة الثعبية واليموقراطية وكلاهما من أهم مقومات النجاح في 
وانعكست ظاهرة العولمة على إدارة المشروعات الزراعية،

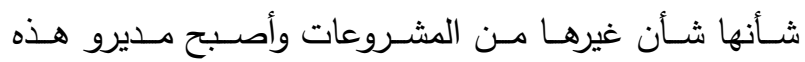

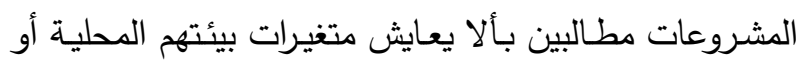

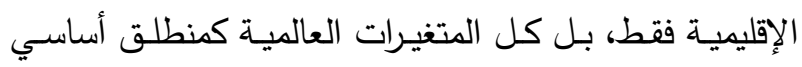
لبلوغ كفاءة فاعلية الأداء الإداري.

\section{r. ثقافة تكنولوجيا المعلومات الزراعية في ظل العولمة:} تكنولوجيـا المعلومـات (IT) هـي أحسث مفرزات التطـور التكنولوجي، وقد أدى تطور تكنولوجيا النقل والاتصـال لإلغاء حواجز الوقت والمسافة بين البلاد، لقد تتامى نقل السلع جوًا وبسرعة بين أسواق متجاورة في دول الاتحاد الأوروبي مثلًا،

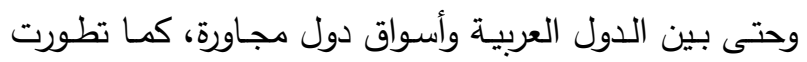
وبسرعة وسـائل الاتصـال الإلكترونيـة لنقل الصـوت والبيانـات متضـــنة البريــــ الإلكترونـي (EM)، والفــاكس، والإنترنــت، وشبكات الاتصال التليفزيوني العالمية السريعة، وهو ما أتاح

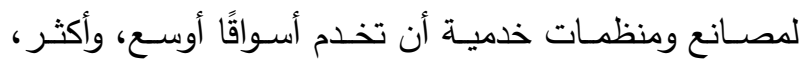
وسمح لشركات أن تركز بعض عملياتها في منطقة معينة مـع

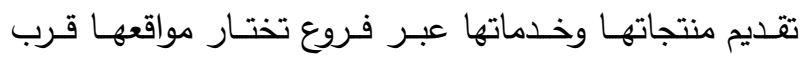

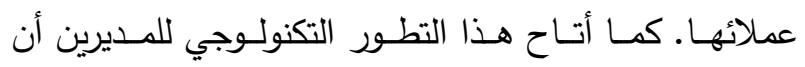
يتصلوا بسرعة حول العالم مما زاد من فرص التعاون وحتى التحالف بين الثركات في صوره المختلفة (فني- تسويقي - مال مالي). وكانت شبكة الإنترنت (شبكة المعلومات العالمية) من أهم مـا أفرزته ثورة تكنولوجيا المعلومات والإنترنت، وهي وسيلة اتصسال إلكترونية مستحدثة حيث إنك تربط تليفونك وحاسبك بوصـلة تسـى "MODEM" "مـوديم" وحتى تتصـل بمصسدر

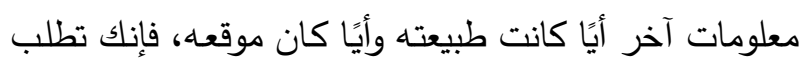
الرقم فتكون مـع مصدر المعلومـة في ثوان معدودة، وبتكلفة مكالمة تليفونية محلية.

وبإيجاز فلقد أدت ثورة التكنولوجيا وتطور وسائل الإعلام،

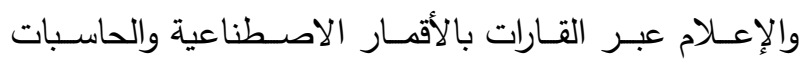

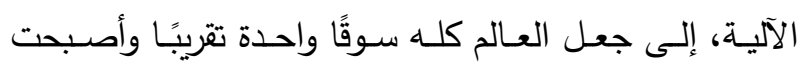

شركاتهم أو في الأسواق العالمية التي يتتافسون فيها، فمثلً

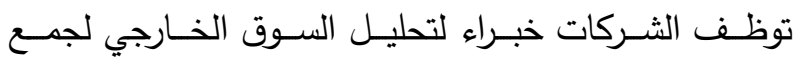
معلومـات عـن المنتجـات الزراعيـة المنافسـة مـن دول أخرى وتوظيفها كأسـاس للتخطيط التسـويقي، والإنتاجي، وقد ترى مـن منظـور اسـتراتيجي عـالمي أن تتكامـل أو تتحسالف مـع شـركة تصدير أخرى أو أكثر بالخـارج ماليًا، أو إنتاجيًا، أو تسويقيًا، أو في صيغة مركبة تشمل أكثر من محور من هذه

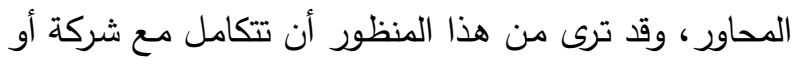
أكثر بالخارج لإنشاء مشروع في بلدك أو في الخارج. John .(10) : (1)) ويتفـق كـل مسن أبـو حطـب (1: ص ع بr) ورشــاد، وآخـرون (T ص: V^) علـى أن ركـائز الثقافـة المعاصـرة

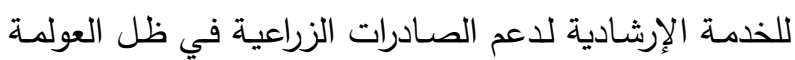
ترتكز على أربع ثقافات هي:

\section{1. ثقافة إدارة الأعمال المزرعية في ظل العولمة:}

تتسع ظاهرة العولمة وتفرض نفسها على قطاعات النشاط الاقتصادي المختلفة والتي يأتي في مقدمتها القطاع الزراعي، والعولمـة هـي انفتاح على العـالم وهـي حركـة متدفقـة ثقافيًا واقتصـاديًا وسياسيًا وتكنولوجيًا، حيث يتعامل مدير المزرعـة اليوم مع عالم تلاشى فيه تأثير الحدود الجغرافية والسياسية. فأمامنا رأسمال يتحرك بغير قيود وبشر ينتقلون بغير حدود ومعلومات تتدفق بغير عوائق حتى تفيض أحيانًا عن طاقة

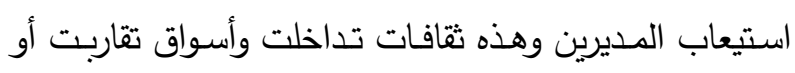
انــدمجت وهـــه دول تكتلــت فأزالــت حـدودها الاقتصــادية والجغرافيـة وشـركات تحالفـت فتبادلـت الأسـواق والمعلومـات والاستثمارات عبر الحدود وهذه منظمات مؤثرة عالميًا مثل وسئل البنـك الـدولي وصـندوق النقـد الـدولي ووكـالات متخصصـة

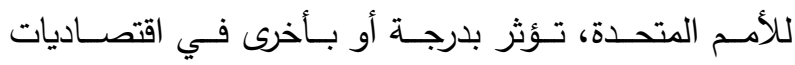
وعمـلات الدول ومستوى وظروف معيشة الناس عبر العالم؛ إنها بيئة جديدة ومثيرة غير مسبوقة يتعامل معها المنتجون والمصدرون. 


$$
\text { مجلة الإسكندرية للتبادل العلمى - (مجلد \& العدد r) ابريل - يونيو ابr r }
$$

التكلفة، ليبيع بأقل سعر في السوق وهدفه ترويج منتجاته

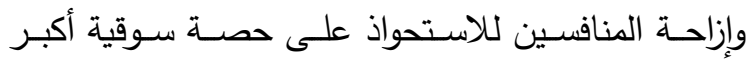
ويسمى الفارق بين السعرين بحد الإغراق.

إلا أن هذه الاتفاقيات شكلت بعض التحديات وأهمها: ( ) زيادة حدة المنافسة في الأسواق المحلية، وكذا الخارجية. r) ارتفـاع فـاتورة التكنولوجيـا المستوردة بعـد تطبيـق اتفاقيـة حماية الملكية الفنية والفكرية التي حظرت تقليد أي سلعة التونيا أو عملية إنتاجية، وعلى ذلك سيمتتع على المستثثر في دولــة ناميـة أن يخطـط للاحتيـال، كمـا فعـل اليابـانيون للحصول على التكنولوجيا اللازمة بتقليد براءات الاختراع وتطويرهـا (الهندسـة العكسية) وسـيكون هـذا صـعبًا، بـلـ ومتعذرًا بعد العمل باتفاقيات "الجات" التي ستحرم التقليد، وتحمي الملكية الفكرية الفنية التي تشمل براءات الاختراع، والأدبية التي تشمل حقوق المؤلفين. ب) إلغـاء الأفضـليات العربيـة - العربيـة مـا لـم تكن الـدول المتمتعـة بالأفضليات داخلـة في سوق مشتركة أو اتحاد جمركي. ع) إلغاء الدعم الحكومي العربي لبعض الصناعات وانتهاء ما

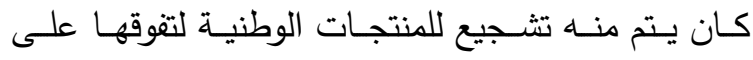
مثيلاتها المستوردة، مما يؤثر سلبًا على المركز السوقي

$$
\text { والتتافسي للشركات العربية. }
$$

ع. ثقافـة إدارة الجـودة الثـاملة ومعـاييز الجـودة العالميـة :ISO 9000

يعتبر مفهوم إدارة الجودة الثاملة من المفاهيم الحديثة في الإدارة، والهدف منها هو تحسين الأداء وتطويره بصورة دائمة من خـلال استجابة المنظمـة لمتطلبات العميل، وتهتم أساسًا بالخامة الأصلية أو النوعية الجيدة وتركز على الكيف- أي: كيفيـة صـنع المنتج - وليس الكم. والذي يعني أن الجـودة متعلقة بتوقعات العميل ومنظوره عن المنتج، وذلك من خلال

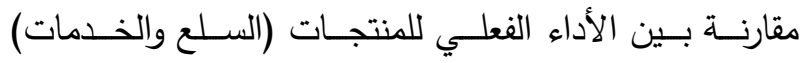

الأسـواق العالميـة أسـرع، وأقوى تأثيرًا بالأحـداث والمتغيـرات السياسية، والاقتصـادية، والفنية، والثقافية، فأصبح أي تطور في سـوق ماليـة رئيسـية مثل بورصــة نيويـورك أو طوكيـو واليه ينعكس في الحال على أسواق مالية أخرى، وأصبح تدهور سعر عملة عالمية رئيسية مدعاة لتدهور فوري لعملات أخرى مرتبطة بها، وأصبح ممكنًا عقد صفقات ضخمة بين طرفين أو أكثر في دولتين أو أكثر دون أن يغـادر أي منهم بلده، وذلك بفضل مؤتمرات واجتماعات الفيديو كونفرانس وأجهزة الفـاكس، وتبـادل ونقـل المعلومـات على شاشـات الحاسبات الآلية.

\section{:G. A. T. T. ثقافة الاتفاقية العامة للتعرفة والتجارة} في أبريـل ؟9 9 ام أعلن بمدينـة مراكش عن قيام النظام التجاري العـالمي الجديد ببدء تتفيذ الاتفاقيـة العامـة للتعرفـة والتجارة "الجات" اعتبارًا من بداية 990 ام وتقضسي الاتفاقية بتحريـر تـدريجي زمنيـا ونوعيًا للتجـارة العالميـة في الســع

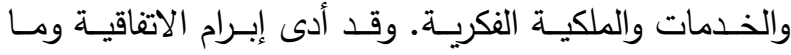
تضـمنته مـن خفض تدريجي للتعرفـة الجمركيـة، ولحصـص الحص الحس الاسـتيراد إلـى الإسـهام فـي عمولـة التجـارة والاسـتثمارات، وجعلها أيسر على نطساق أسواق الدول الأعضـاء في هذه الإنه

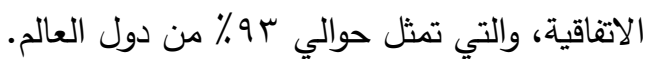
وقد هيأت اتفاقيات الجات عدة مزايا أو فرص للدول النامية

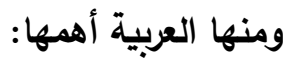
ا ـ إفادة الصـادرات من تخفيضـات جمركية في الدول التي تصدر إليها يبلغ متوسطها سז٪. r. إلغاء تدريجي على مدى عشر سنوات لنظام الحصص الذي كانـت تفرضــه الـدول المتقدمـة على وارداتهـا مـن الملابس والمنسوجات.

r. حمايـة إزالــة ممارسـات الإغـراق فـي الأسـواق العربيـة وتتوافر حالة الإغراق Dumping، عندما يخفض المنتج أو المصدر أو التاجر - بشكل عـام - سعر بيع المنتج في السـوق المستهدفة عـن سـر السـوق أو حتى عـن 
0- توعية الزراع بأهمية العناية بجودة المنتج، وكذلك الاهتمام

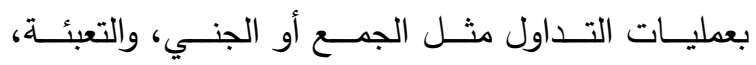
والتغليف، والتخزين، وتأثير ذلك على تسعير هذا المنتج سواء في السوق المحلي أو الخارجي، مما ينعكس ويؤثر تأثيرًا مباشرًا في رفع مستوى معيشة المزارع. 7- العمل على تكوين قاعدة معلومـات وبيانات وإحصـاءات

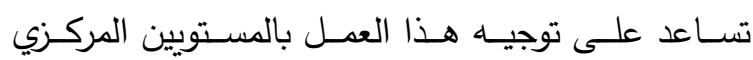
والمحلي للوصول إلى الأهداف المطلوبة. V- إصدار نشرات إرشادية تسويقية على فترات تتزامن مـع مواسم نضج المحاصيل المختلفة والعروات الموسمية. ^- دراسة التوقعات السعرية وتعريف الزراع بها، فالمزارع يقوم عادة بزراعة المحصول الذي يرتفع سعره في موسم معين،

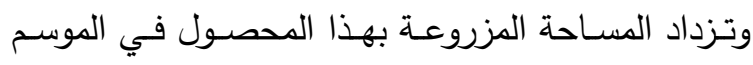

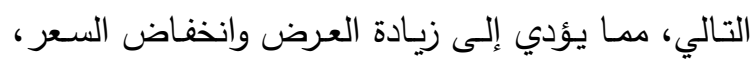
وتحقيق خسـارة مؤكدة، وفي هذا المجـال تكـون دراســة

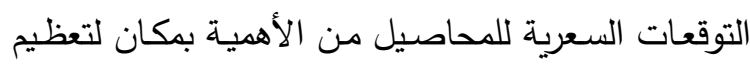
قيمة المنتج الزراعي، وتجنب الخسارة. هذا وقد تم اختيار

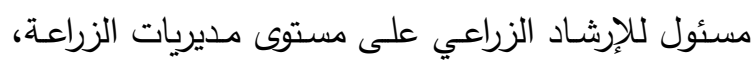
وجاري إعداد برنامج تدريبي لهم يشترك فيه الباحثون من

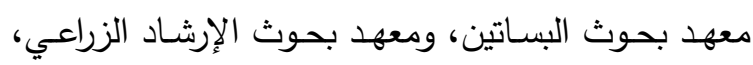
بالاشتراك مع معهد بحوث الاقتصـاد الزراعي في تصميم

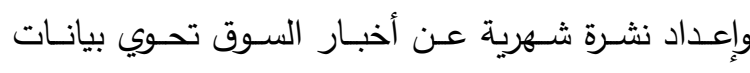
ومعلومـات تسـاعد منتجي الخضـر والفاكهـة على وضـع سياستهم التسويقية بما يحقق لهم عائدًا مجزيًا، كما تحوي تحركات أسعار أغلب المحاصيل المتواجدة في الأسواق، ومقارنة أسعار كل محصول في الأسواق من خلال رسوم

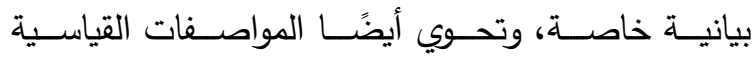
للنوعيات الممتازة على معرفة السعر الذي يجب الحصول ولي لإله عليه إذا قام بعمليات الفرز والتدريج. 9 - إبـلاغ المحافظـات بنشـرة يوميـة عن أسـعار الجملـة في

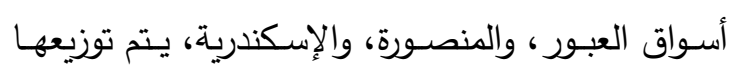

والتوقعات المرجوة من المنتج فإذا كانت المواصفات النهاية للمنتج مطابقة لتوقعات العملاء أو المستهلكين نستطيع القول بأن المنتج قد حقق هدف الجودة. ولتحقيق ذلك فقد وضـعت المنظمـة الدوليـة للمواصفات

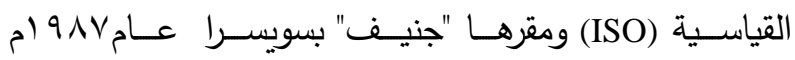
مواصـفات قياسية عالميـة اتفقت دول المجموعـة الأوروبيـة بشـكل خـاص والـدول الصـناعية الكبـرى بشـكل عـام على في توحيـدها لكافـة المنتجـات فيمـا عـدا المنتجـات الكهربائيـة والغذائية، ووضـعت المنظمـة الدولية الكهربائية الفنية (IEC)

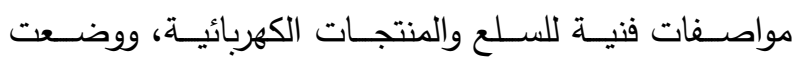
المنظمـة الدوليـة لدسـور الأغذيـة (CAC) مواصـفات فنيـة للسلع والمنتجات الغذائية، والحبوب، والمضـافات، والملونـات الغذائية، وحدود المواد الضـارة بالصحة العامة، وكذلك حدود

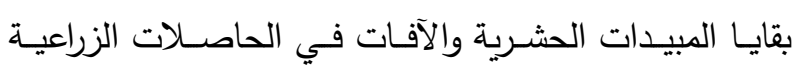
والمنتجات الغذائية.

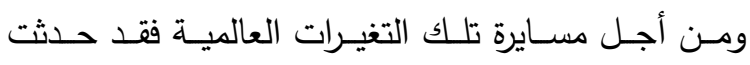
تطـورات فـي هيكـل الإدارات الإرشـادية بـالإدارة المركزيــة للإرشاد الزراعي (ץ: وزارة الزراعة) نوجزها فيما يلي: فقد تم إنشـاء إدارة الإرشـاد التسويقي عام 999 ام داخل الهيكل التتظيمي وتحددت لها المهام التالية: ا - تدريب جهاز قادر على أن يكون حلقة وصل فعالة بين المسترشدين ومراحل العمل التسويقي. r- تحديد الاحتياجـات التسويقية بناء على دراسـات ميدانية تُجرى في عدد من المحافظات التي تعاني من المشاكل التسويقية كهدف عاجل على أن يتم التوسع بعد ذلك في باقي المحافظات كهدف آجل. "- تخطيط نظـام متكامل لتوزيع السـلع والخدمات وتسعيرها بالتتسيق مـع الأجهزة الأخرى في هذا المجـال، وكذلك تعريف المستهلك بأماكن تواجدها. ع - تخطيط وتتفيذ برامج إرشادية في مجال العمل التسويقي

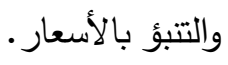




$$
\text { مجلة الإسكندرية للتبادل العلمى - (مجلد \& العدد r) ابريل - يونيو ابr r }
$$

المعرفة في القرية المصرية، حيث إن نجاحه يكمن في توسيع نطاق مهمتهـه ودوره الإرشـادي وفي قدرتـه على التعامل مـع

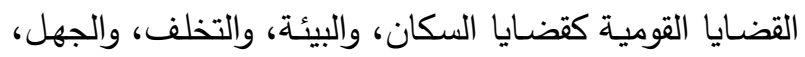
والمرض، بالإضـافة إلى مهامـه الأساسية في قضـايا الإنتاج،

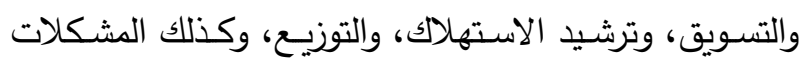

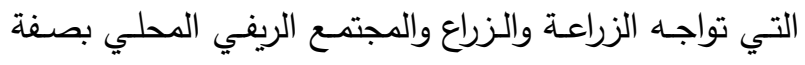

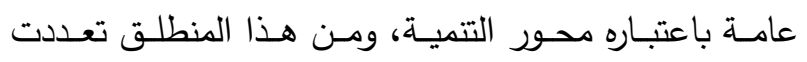
وتباينت أدوار الإرشاد الزراعي, ولم تعد مقتصرة على عمليات

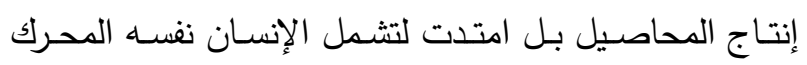

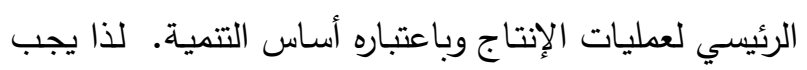

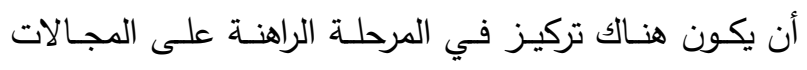

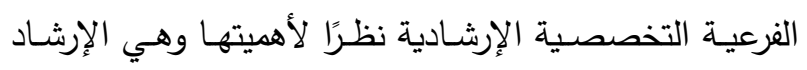

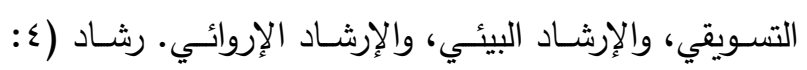
ص ( )

\section{أهداف البحث}

اسـتهدف البحـث بصـفة رئيسـية دراسـة الـدور الحـالي والمستقبلي للإرشاد الزراعي التسويقي في ظل سياسة التحرر الاقتصادي (العولمة) من وجهة نظر المهندسين الزراعيين في

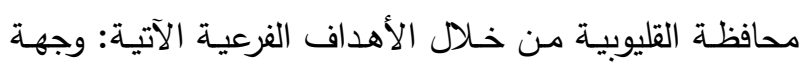
نظر المهندسين الزراعيين. ا ـ تحديـد مـدي إدراك المهندسـين الـزراعيين لـدور الإرشـاد الزراعي الحالي والمستقبلي في مجال الإرشاد التسويقي

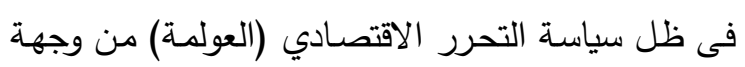
نظر المهندسين الزراعيين في محافظة القليوبية.

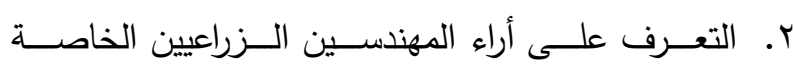
بـالنهوض بمهـامهم في مجـال الإرشـاد التسـويقي فيــا

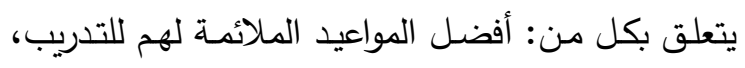
ومكان إقامة الدورات التدريبية، والطرق المفضلة لهم في لهي التدريب، والمدربين القائمين بالتدريب.

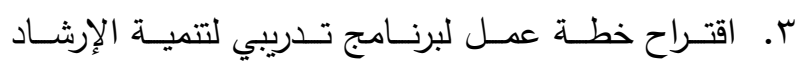

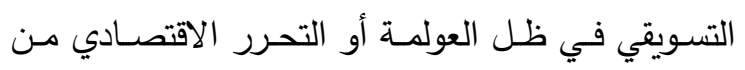

على المراكز الإدارية ويتم تعليقها على لوحة مخصصة

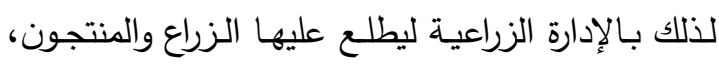

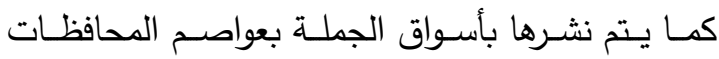

لاطلاع التجار عليها.

• 1 - التنسـيق مـع وسـائل الإعـلام المختلفـة لبــث النشـرة اليومية لأسعار الخضر والفاكهة.

وفي ظل التوجهات الاقتصادية للدولة في القطاع الزراعي، والتي تستهدف تحقيق مزيد من التحرر الاقتصادي

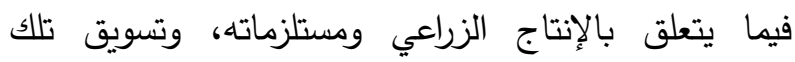
المنتجات، وفي ضوء الاتفاقيات الدولية الخاصة بحماية المستهلك وحرية المنافسة، ومنع الاحتكار ، ووضع مواصفات

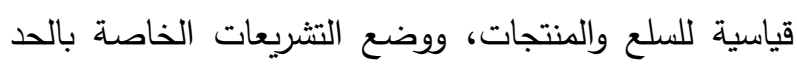
من التلوث، وحماية البيئة وصيانتها، كان من الضروري على جهاز الإرشاد الزراعي أن يطور من نفسه ومن نوعية الخدمة التي يقدمها لجمهور المسترشدين، وأن يقتحم مجالات أخرى غير تقليدية استلزمتها ظروف الواقع المعاصر الذي يمر به العالم الأن. محروس (^: ص لVم).

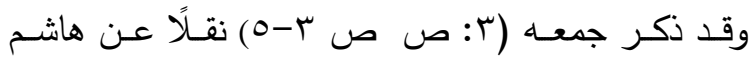
والسلمي، أن السلوك الإنسـاني يتحدد إلى درجـة كبيرة تبعًا

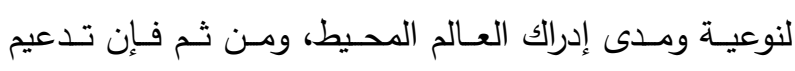
السلوك الإنساني أو تغيره يتطلب معرفة كيفية إدراك الفرد ما يدور حوله، ولا يستطيع الفرد تكوين اتجاه نحو أي شيء أو الو لئي

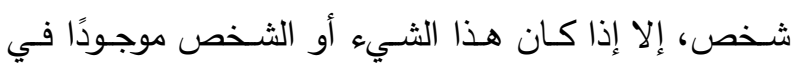
محيط إدراكه. ويختلف إدراك الأفراد اختلافًا ملحوظًا من فرد إلاء إلى أخر نحو نفس الموقف، وقد يكون مرجع ذلك أن الناس تدرك الحقـائق في ضـوء ظروفها ومشكلاتها، واهتماماتها، وخلفيتها المعرفية (BACK GROUND) كما أنها تميل إلى إهمال التفاصيل التي لا تتلاءم مع حاجاتها الثخصية. ويضيف جمعه (r: ص: V) نقلا عن شرشر ، أن إدراك مستقبل العمل الإرشادي الزراعي يعتمد على دوره الفاعل في

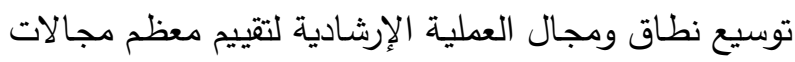


الدور الحالي للإرشاد الزراعي في مجال الارشاد التسويقي:

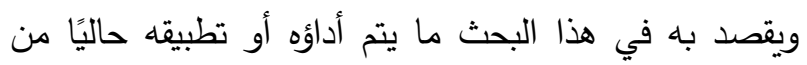
أنثطة إرشادية في مجال الإرشاد التسويقي. مجالات البحث (المكاني، والبثري، والزماني):

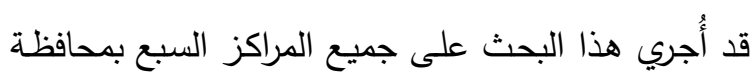

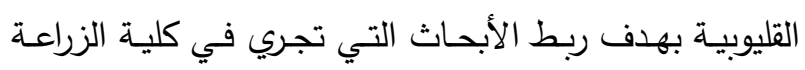

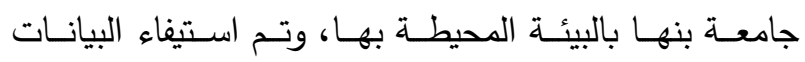
الميدانيـة مـن خـلال مديريــة الزراعـة بالقليوبيـة، والمركـز

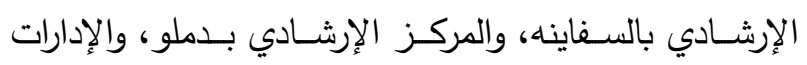

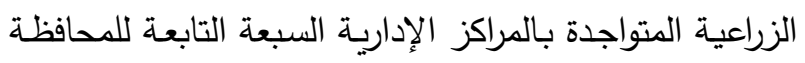

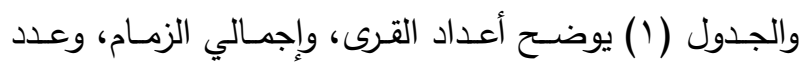

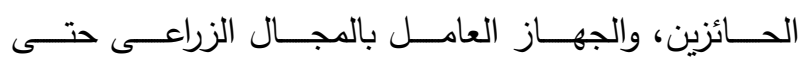
r. r. T./T/r

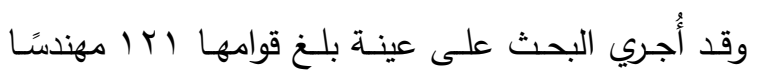

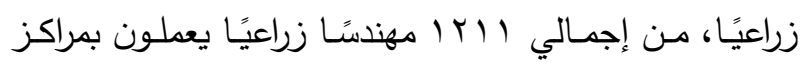

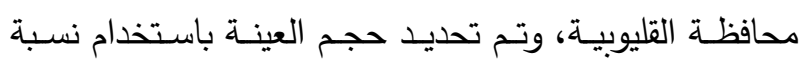

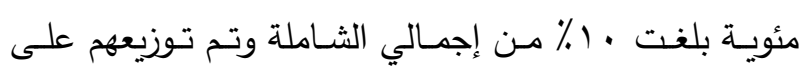

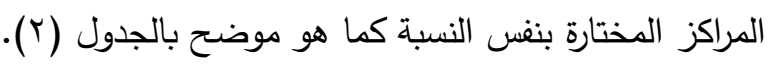
وقد استخدم الاستبيان كأداة لجمع البيانات اللازمة لتحقيق

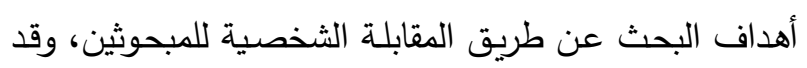

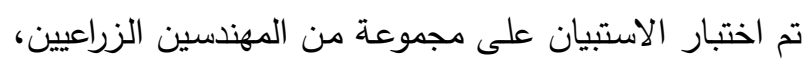

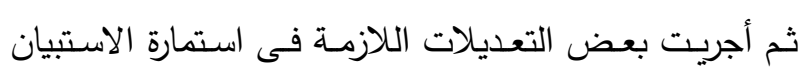

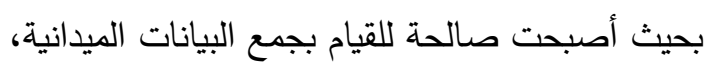

وجهــة نظـــر المهندسـين الـزراعيين وفقــا لصــفاتهم

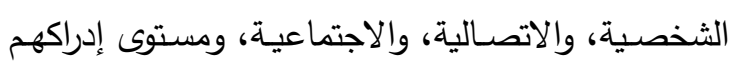

$$
\text { للدور الإرشادي التسويقي. }
$$

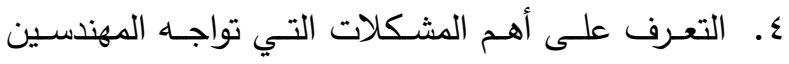

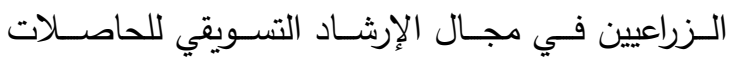

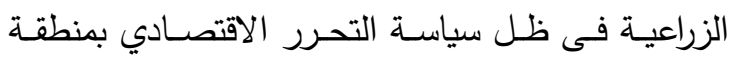

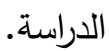

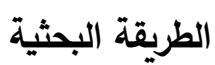

نوع البحث وإلمنهج المستخدم:

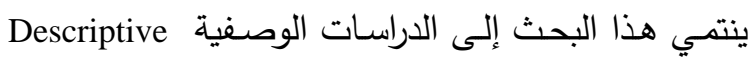

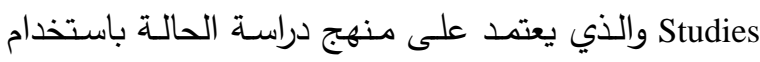

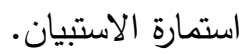

ثانيًا: التعريفات الإجرائية لبعض المصنيان المطات المستخدمة في الدراسة:

المجالات الإرشادية المستحثثة فى ظل سياسة التحرر الاقتصادي: ويقصد بها في هذا البحث مجالات العمل

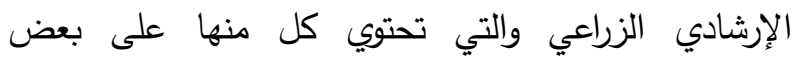
الأنشطة الإرشادية التي ينثأ عن تتفيذها تحقيق الأهداف الإنافي الإرشادية المنشودة ومنها مجال الإرشاد التسويقي. الأنثطة الإرشادية: ويقصد بها في هذا البحث الخدمات

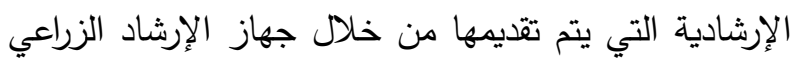

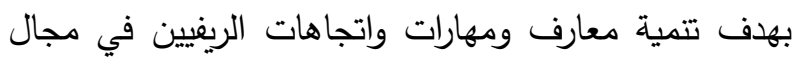
الإرشاد التسويقي. 


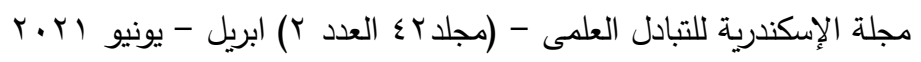

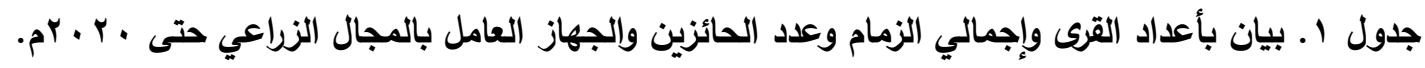

\begin{tabular}{|c|c|c|c|c|c|c|c|}
\hline \multirow{2}{*}{ الإجمالي } & \multirow{2}{*}{ فني زراعي } & \multirow{2}{*}{ أزخرائي } & \multirow{2}{*}{ القرى } & \multirow{2}{*}{ عدد الحائزين } & \multicolumn{2}{|c|}{ جملة الزمام المزروع } & \multirow{2}{*}{ ل لمركز } \\
\hline & & & & & فذان & قيراط & \\
\hline rqA & TYY & VY & $\varepsilon r$ & 0.109 & TrTIA & $1 \varepsilon$ & بنها \\
\hline$\Lambda \Lambda$ & 79 & 19 & rr & $r \leq V O V$ & Mros & 9 & كفر شكر \\
\hline$r \cdot \Lambda$ & 107 & or & $\varepsilon_{0}$ & VTILT & $\leqslant \varepsilon .19$ & r & طوخ \\
\hline זrו & 110 & 11 & rr & rovol & TrOSA & ir & قليوب \\
\hline 99 & Av & IT & 19 & IVYr. & IAVTV & 11 & التناطر - - ماطر \\
\hline 107 & 111 & $\leqslant 0$ & ro & rqई & ros7 & 1 & شبين القناطر \\
\hline rrq & $r \cdot \Lambda$ & r) & ir & $1 \pi \leqslant 0$. & $10 . . r$ & --- & الخانكة \\
\hline 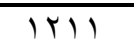 & $\overline{9 V Y}$ & $\overline{r q q}$ & 199 & TERTVT & WVIOVA & 79 & الإجمهالي \\
\hline
\end{tabular}

المصدر : مديرية الزراعة ببنها، محافظة القليوبية، بيانات غير منشورة.

جدول r. التوزيع العدىى والنسبى للمهندسين الزراعيين المبحوثين على مستوى مراكز المحافظة.

\begin{tabular}{|c|c|c|c|}
\hline حجم العينة المطلوبة & عدد المهنسين & 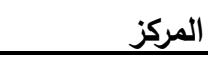 & المحافظة \\
\hline r. & $r q \Lambda$ & بنها & \\
\hline 9 & M & طوخ & \\
\hline YI & $r \cdot \Lambda$ & قليوب & \\
\hline IT & Trו & كفر شكر & القليوبية \\
\hline 1. & 99 & شبين القناطر & \\
\hline 10 & 107 & القناطر الخيرية & \\
\hline r & rrq & الخانكة & \\
\hline$|r|$ & $|r| 1$ & & الإجمالى \\
\hline
\end{tabular}

المصدر : مديرية الزراعة ببنها، محافظة القليوبية، بيانات غير منشورة.

وثانيهــا: يتصـل بالأسئلة المتعلقـة بـالأداء أو التطبيقت الحالي والمستقبلي للأنثطة الإرشادية المتعلقة بمجال الإرشاد

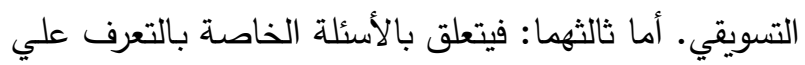
آراء المهندسين الزراعيين فيما يتعلق بالمواعيد الملائمة لإقامة

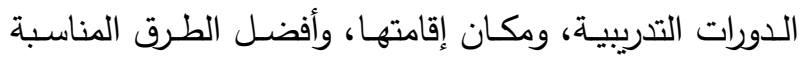

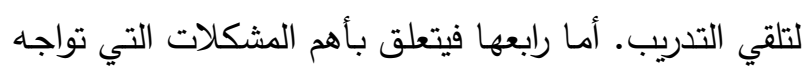
المهندين الزراعيين المبحوثين والتي تقف حجر عثرة فئرئ سبيل تحقيق الأهداف المتعلقة بأنشطة الإرشاد التسويقي.

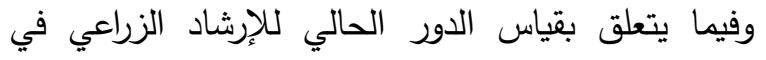
مجال الإرشاد التسويقي فقد تم من خلال توجيه عدة أسئلة

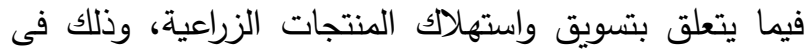

وقد تم جمـع البيانات خـلال الثلاثة أشهر الأخيرة من عام

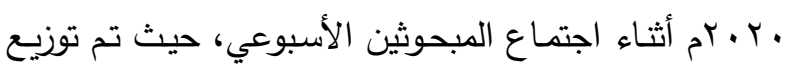

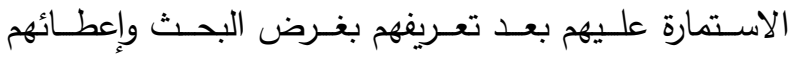
التوجيهـات اللازمــة لضـمان اسـتيفاء الاسـتمارة وتحقيقهـا لأهداف البحث، وقد اشتملت صحيفة الاستبيان على ثلاثة أجزاء تضمن أولها: سؤال المبحوثين عن عدد من الصفات

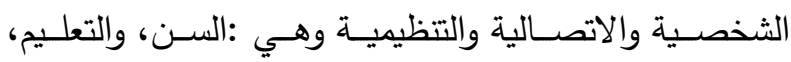

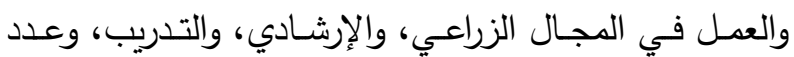
مراته، والمصـادر التي يستقي منها معلوماتـه في تسويق الهـيق الحاصلات في المجال الزراعي. ولئ. 
التوصل إليها، وكذا الأدلة والثواهد التي يمكن اقتراحها عند تقييم الخطة التدريبية من وجهة نظر البحث.

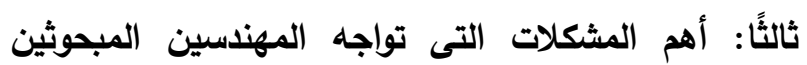
والتى تقف حجر عثرة فى سبيل تحقيق الأهداف المتعلقة بأنشطة مجال الاراسة:

تم حصر المشكلات الواردة فى استجابات المهندين الزراعيين المبحوثين وترتيبها من حيث الأهمية على ضوء التكرارات، والنسب المئوية وأهم هذه المشكلات هى:

أولًا: مشكلات تواجه العمل الزراعي وهي: ضعف دور الجمعيات التعاونية الزراعية فى توفير

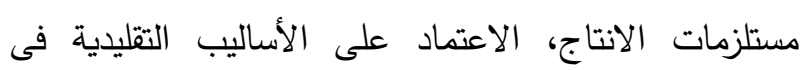
الزراعة، ارتفاع تكلفة الانتاج الزراعي، غياب دور الجمعيات

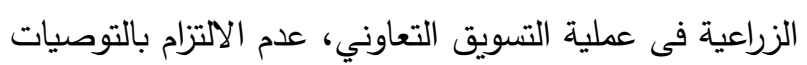

ثانيًا: مشكلات تواجه العمل الإرشادي وهي: عدم وجود نشرات سعرية دورية، عدم كفاية النشرات والملصقات الإرشادية، ضعف الاهتمام بمشاركة القيادات الريفية فى عملية التتمية، عدم مناسبة البرامج الإرشادية لتلبية احتياجات الثباب الريفى، ضعف التعاون بين الجهاز الإرشادي والمؤسسات الخدمية الأخرى.

ثالثًا: مشكلات خاصة بالموارد البشرية الإرشادية وهي:

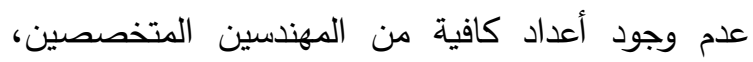
انخفاض كفاءة بعض المهندين وقلة خبرتهم، إقحام المهندسين فى الأعمال الإدارية.

رابعًا: مشكلات خاصة بالموارد المادية الإرشادية وهي:

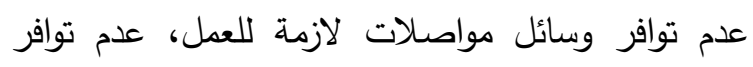

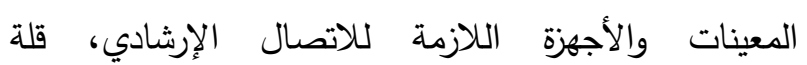
الاعتمادات المالية اللازمة للعمل.
صورة أنشطة إرشادية تم صياغتها على هيئة أهداف إرشادية

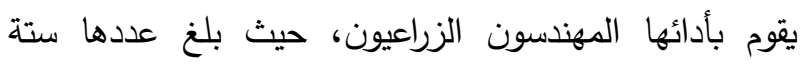
نشاطات إرشادية فى مجال الإرشاد التسويقي المدروس، حيث سئل المهندسون هل يتم تطبيق الأنشطة من جانبهم فى الوقت الحالي؟، وما حجم الدور الإرشادي في الوقت الحالي

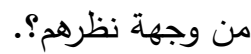
وعند استجابة المهندس الدالة على التطبيق أُعطي (درجتان)، وفى حالة عدم التطبيق أُعطي (درجة واحدة)، كما أعطي عند استجابته فيما يتعلق بحجم الدور الإرشادي فإذا

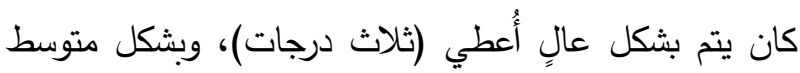
أعطي (درجتان)، وبشكل منخفض أعطي (درجة واحدة)، وللحصول على الدرجة الكلية المعبرة عن الدور الحالي للإرشاد الزراعى، فقد أضيفت الدرجة المعبرة عن تطبيق النشاط من عدمه إلى الدرجة الدالة على حجم الدور الإششادي لتعبر عن الدور الإرشادي في هذا النشاط، ثم

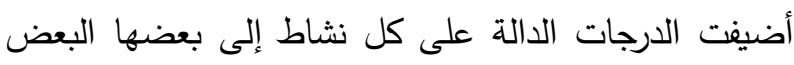
ليتم الحصول على درجة كلية تعبر عن الدور الإرشادي

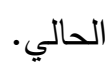
أما فيما يتعلق بالحصول على الدرجة المعبرة عن الدور المستقبلي للإرشاد الزراعي، فتم قياس ذلك بسؤال المهندسين الزراعيين عن درجة رؤيتهم المستقبلية لدور الإرشاد الزراعي التسويقي، ففي حالة استجابته الدالة على أنه يجب زيادة الدور بشكل عالٍ أعطي (ثلاث درجات)، وفى حالة زيادته بشكل متوسط أعطي (درجتان)، وفى حالة زيادته بشكل منخفض أعطي (درجة واحدة)، وبجمع الدرجات التي حصل

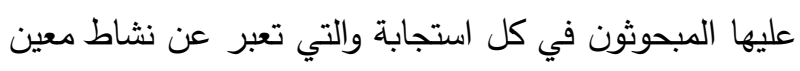
إلى بقية الأنشطة المدروسة أمكن الحصول على درجة كلية تعبر عن الدور المستقبلي للإرشاد الزراعي في مجال الإرشاد التسويقي. هذا وقد تم اقتراح خطة عمل للبرنامج التدريبي في الإرشاد التسويقي من خلال المؤشرات الواقعية التي تم 


$$
\text { مجلة الإسكندرية للتبادل العلمى - (مجلد \& العدد r) ابريل - يونيو ابr r }
$$

1028

الإرشاد التسويقي وهو المتعلق باستهلاك وتسويق الحاصلات الزراعية، وفيما يلي عرض لأهم النتائج المتعلقة بحجم الدور الإرشادي المتصل بالأنشطة المتعلقة بهذا المجال بشكل تفصيلي. - مجال تسويق واستهلاك الحاصلات الزراعية: لتحديد حجم الدور الحالي للإرشاد الزراعي في مجال تسويق واستهالك الحاصلات الزراعية، فقد تم سؤل تلتيل المهندسين الزراعيين المبحوثين عن عدد من العبارات بلغ عددها ست عبارات كما هو وارد بالطريقة البحثية، وباستخدام مجموع قيم العبارات التي تم الحصول عليها من استجابات المبحوثين علي هذه البنود أو العبارات البالغ عددها ست عبارات، فقد تم الحصول على درجة كلية تعبر عن حجم الدور الحالي الإرشادي، وقد انحصرت درجات الدور

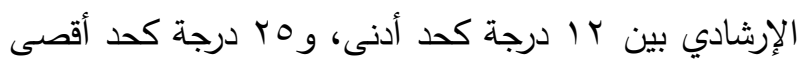
بمتوسط حسابي قدره ؟.. ب درجة، وانحراف معياري قدره r,r، وقد تم تقسيم المبحوثين من حيث درجة الدور الحالي للإرشاد الزراعي إلى ثلاث فئات كما هو مبين بالجدول (r).

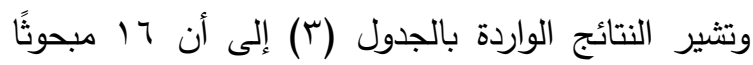
يمثلون r.r \% من إجمالي المبحوثين يدركون أن حجم الدور

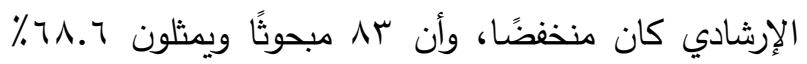
يرون أن حجم الدور الإرشادي كان متوسطًا،
خامسًا : مشكلات تتعلق بالرضا الوظيفي وهي: ضآلة المرتبات وعدم مناسبتها لطبيعة العمل، وقلة الحوافز والأجور الإضافية. ولتحديد أولويات مشكلات المهناسين المبحوثين والتى تقف حجر عثرة فى سبيل تحقيق الأهداف المتعلقة بأنشطة مجال الدراسة، فقد تم ذلك من خلال حساب التكرار والنسب المئوية ومن ثم معرفة الترتيب الداخلى، والترتيب العام لتلك المشكلات التى تواجه المهندين المبحوثين، وبذلك أمكن ترتيب المشكلات تتازليا من حيث درجة الأهمية. سادسًا: أدوات التحليل الإحصائي: تم جمع البيانات وتبويبها وجدولتها ثم استخدام بعض الإسلة المقاييس الإحصائية المناسبة لتحليلها مثل المتوسط المرجح، واستخدام التكرارات، والعرض الجدولي، والنسب المئوية لعرض المتغيرات البحثية، وذلك بما يحقق الأهداف البحثية المدروسة وقد تم تحليل البيانات بواسطة الحاسب الآلى

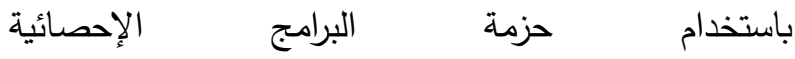
.(Spss11) Statistical Package for social sciences

\section{النتائج ومناقشتها}

الدور الحالي للإرشاد الزراعي في مجال الإرشاد التسويقي:

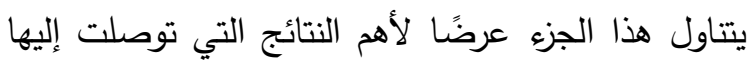
الدراسة فيما يتعلق بدور الإششاد الزراعي الحالي في مجال

جدول ب. توزيع المبحوثين وفقا لحجم الدور الحالي للإرشاد الزراعي في مجال تسويق واستهلاك الحاصلات الزراعية

\begin{tabular}{|c|c|c|}
\hline النسبة المئوية \% & 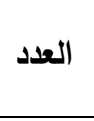 & حجم الدور الإرشادي \\
\hline Ir.r & 17 & منخفض (أقل من VI درجة) \\
\hline 71.7 & N & متوسط (من IV - أقل من اY درجة) \\
\hline $1 \wedge . r$ & rr & مرتفع ( اب درجة فأكثر) \\
\hline $1 \cdots$ & $|r|$ & 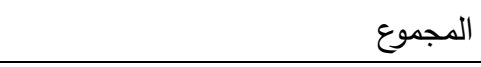 \\
\hline
\end{tabular}


r. أنثطة إرشادية ذات دور متوسط في أدائها وهي: تطبيق

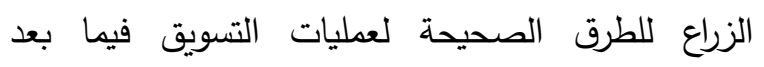

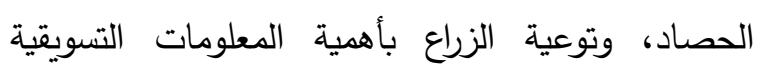

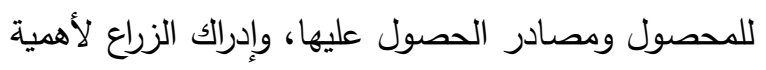

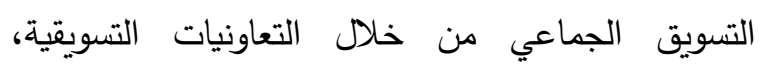

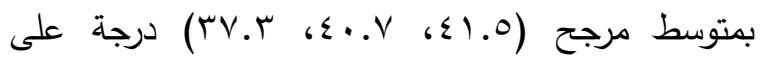
الترتيب.

r.أنثطة إرشادية ذات دور منخفض في أدائها وهي:

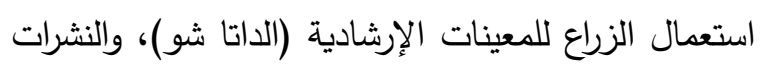

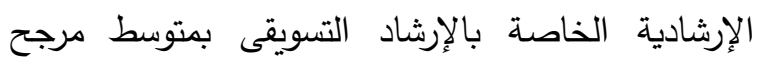

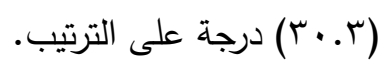

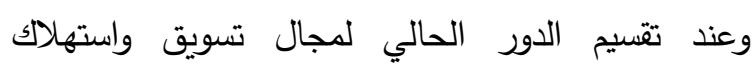
الحاصلات الزراعية إلى ثلاث فئات وفقا لدرجة أداء

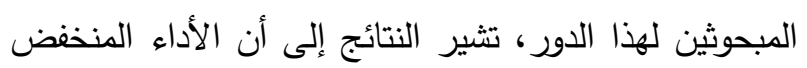

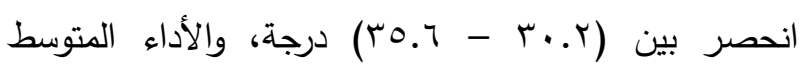

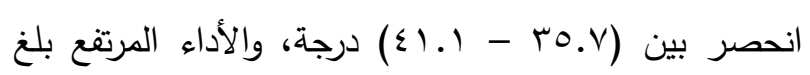

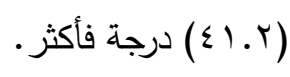

- الدور المستقبلي للإرشاد الزراعي في مجال الإرشاد

\section{التسويقي المتعلق بالأنثطة المدروسة المبنة}

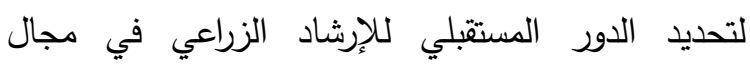

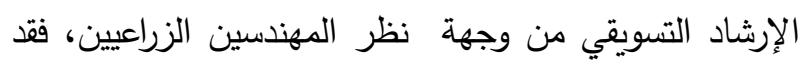

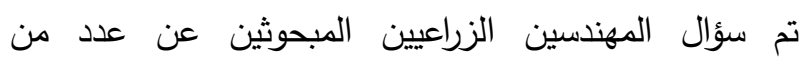

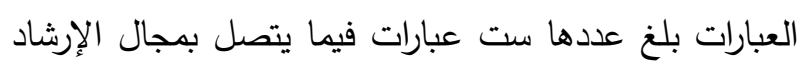

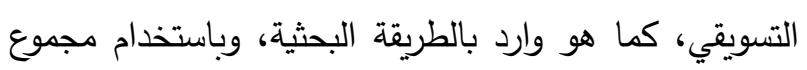
قيم العبارات التي تم الحصول عليها من استجابات المبحوثين

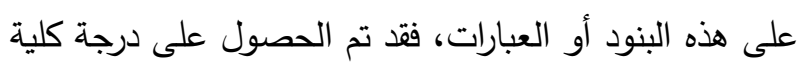
تعبر عن حجم الدور المستقبلي للإرشاد الزراعي في المجال

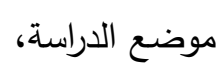

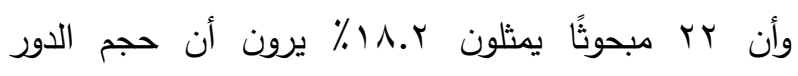

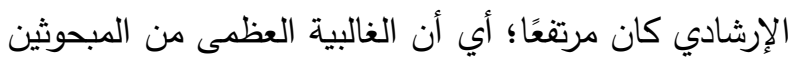

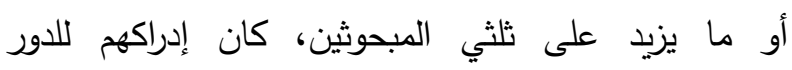

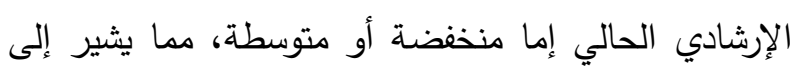
الانخفاض النسبي الكبير في الأداء من جانب الإنب العاملين الإنين

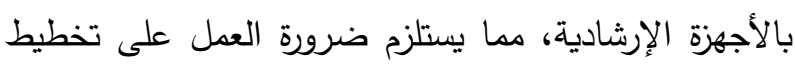

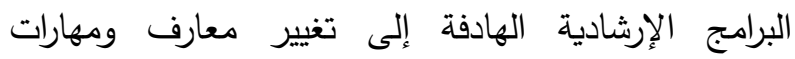
واتجاهات المهندسين الزراعيين نحو العمل في تتفيذ أنثطة

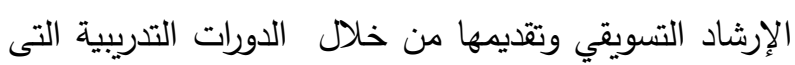
تعقد لهم في هذا المجال. ولتحديد الأنثطة الواجب التركيز عليها وفقا لحجم الدور

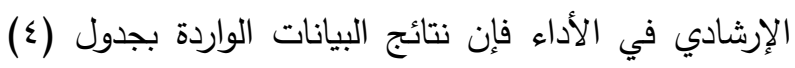

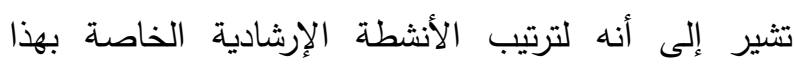

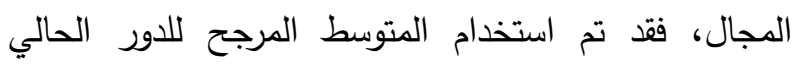

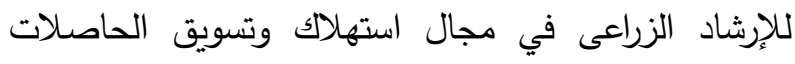
الزراعية من وجهة نظر المهندسين الزراعيين، وقد جاء

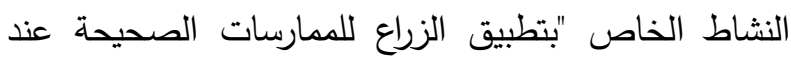

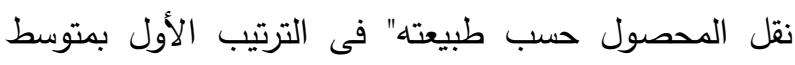

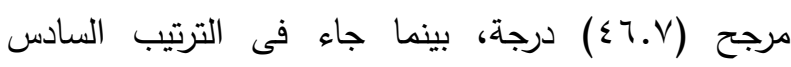
والأخير النشاط الإرشادي الخاص "باستعمال الزراع للمعينات

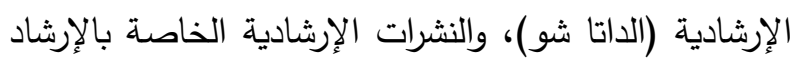

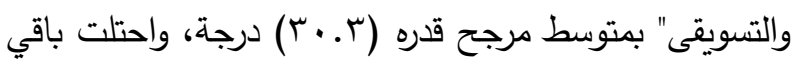
الأنثطة الإرشادية الترتيب من الثاني إلى الخامس، كما هو

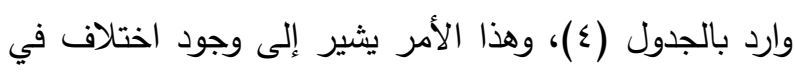

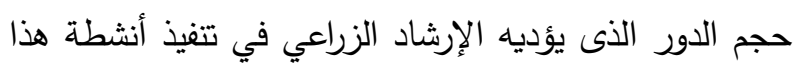

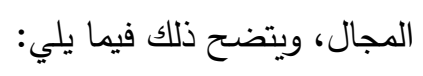

1. أنثطة إرشادية ذات دور كبير في أدائها وهي: تطبيق

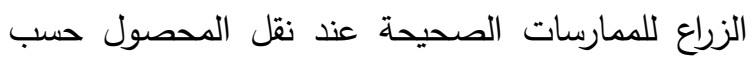
طبيعته، وتعلم الزراع للممارسات الصحيحة فى التخزين

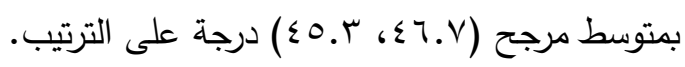


جدول ع. ترتيب الأنشطة المتعلقة بمجال تسويق وإستهلاك الحاصلات الزراعية وفقا لحجم الدور الإرثادى من وجهة نظر المهندسين الزراعيين.

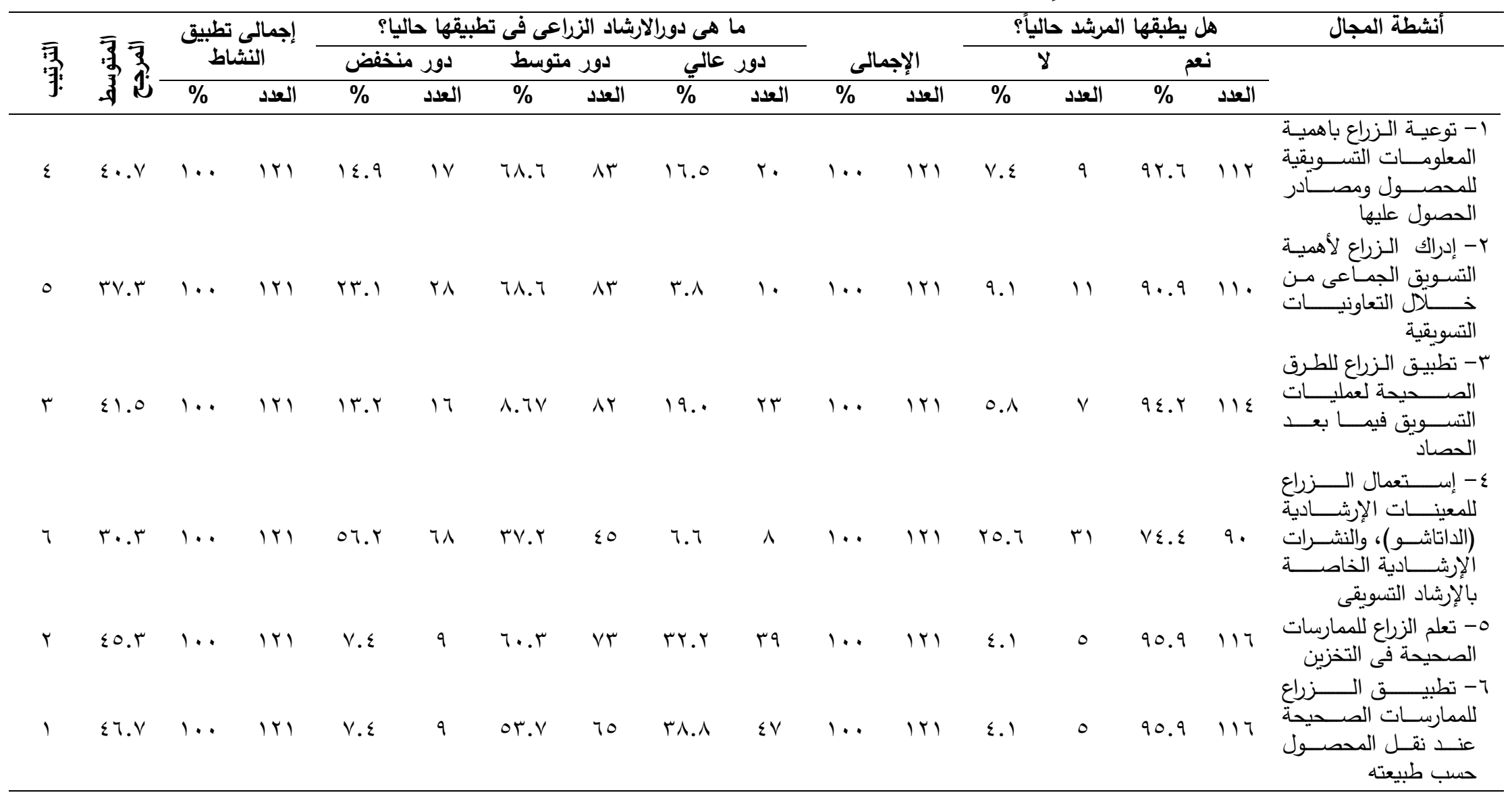


التخزين" بمتوسط مرجح قده ( (. . (1)) درجة، وجاء في

الترتيب الثالث "تطبيق الزراع للممارسات الصحيحة عند نقل المحصول حسب طبيعته" بمتوسط مرجح قدره ^. ال د درجة، ثم في الترتيب الرابع " تطبيق الزراع للطرق الصحيحة لعمليات التسويق فيما بعد الحصاد" بمتوسط مرجح قدره V. آ درجة، وجاء في الترتيب الخامس "تقهم الزراع لأهمية التسويق الجماعي من خلال التعاونيات التسويقية" بمتوسط مرجح قدره س. .7 درجة، بينما جاء في الترتيب السادس والأخير النشاط الإرشادي الخاص "باستعمال الزراع للمعينات الإرشادية (الداتا شو)، والنشرات الإرشادية الخاصة بالإرشاد التسويقى" بمتوسط مرجح قدره (OV.V. ) درجة.
وقد تم ترتيب الأنشطة داخل المجال وفقًا للمتوسط المرجح المتحصل عليه من الدرجات الفعلية لحجم الدور المستقبلي من وجهة نظر المهندسين الزراعيين لكل نشاط كما يلي: مجال الإشاد التسويقي (تسويق واستهلاك المنتجات (الزراعية):

تشير نتائج البيانات الواردة بالجدول (0) إلى ترتيب

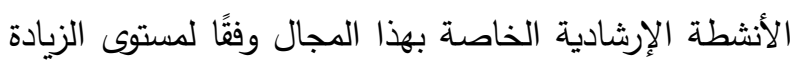
فى حجم الدور المستقبلى للإرشاد الزراعي، وقد جاء النشاط

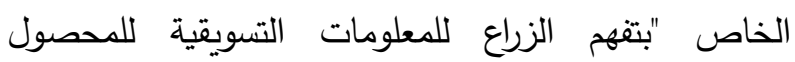
ومصادر الحصول عليها" فى الترتيب الأول بمتوسط مرجح

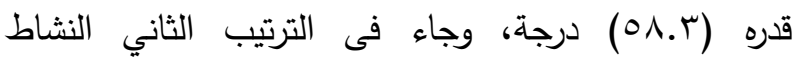
الإرشادي الخاص "بتعلم الزراع للممارسات الصحيحة فى وه

جدول ه. الترتيب والمتوسط المرجح وفقًا لحجم الزيادة في الدور المستقبلي لأنشطة مجال الإرشاد التسويقى من وجهة نظر المهندسين الزراعيين المبحوثين

\begin{tabular}{|c|c|c|c|c|c|c|c|c|c|c|}
\hline \multirow{3}{*}{ 浑: } & \multirow{3}{*}{ 牙示 } & & & \multicolumn{6}{|c|}{ هل ترى مستقبليًا زيـادة في هذا الدور الإرشادي؟ } & \multirow{3}{*}{ أنشطة المجال } \\
\hline & & & & \multicolumn{2}{|c|}{ زميادة بشكل } & \multicolumn{2}{|c|}{ زيادة بشكل } & \multicolumn{2}{|c|}{ 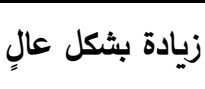 } & \\
\hline & & $\%$ & العدد & $\%$ & العدد & $\%$ & العدد & $\%$ & العدد & \\
\hline 1 & O^.r & $1 \ldots$ & $|Y|$ & r.r & $\varepsilon$ & $\varepsilon .1$ & 0 & 94.7 & 115 & التسويقية للمحصن الزراع للمعلومات ومصادر \\
\hline 0 & 07. & $1 \cdots$ & $|Y|$ & r.o & r & IV.z & YI & $\Lambda \cdot . r$ & $9 V$ & الجماعي تفه الزراع لأهمية التسويت خلات التعاونيات \\
\hline$\varepsilon$ & ov.. & $1 \ldots$ & $|Y|$ & r.o & r & IY. & 10 & 10.1 & $1 . r$ & 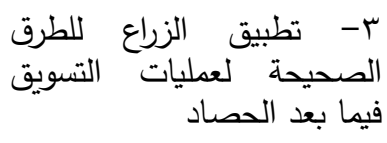 \\
\hline 7 & or.. & $1 \ldots$ & $|Y|$ & 7.7 & $\Lambda$ & $r \varepsilon \ldots$ & $r q$ & 79.8 & $\Lambda \varepsilon$ & 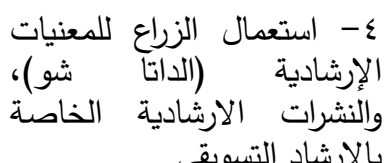 \\
\hline$r$ & O^.. & $1 \ldots$ & $|Y|$ & 1.8 & $r$ & 9.1 & 11 & ᄉ & $1 \cdot 1$ & الصحيحة في التخزين \\
\hline$r$ & OV.r & $1 \ldots$ & $|Y|$ & $r, 0$ & r & $1 . . V$ & rו & $\wedge 7 . \wedge$ & 1.0 & ح- حسبحة طبيق الزراع للمدارسات المحصول \\
\hline
\end{tabular}


و . مــا يقـرب مـن ثلــث المهندسـين الـزراعيين المبحــوثين

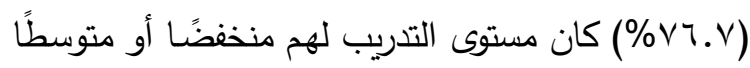

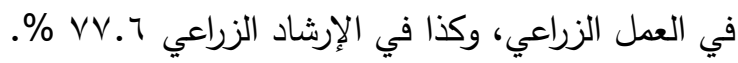
ز. انخفاض مستوى تعرض المهندسين الزراعيين المبحوثين

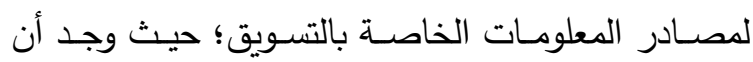

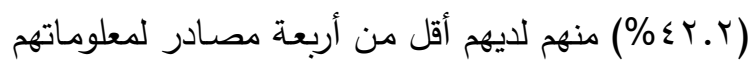

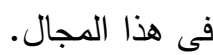
ح. أن المهندسين الزراعيين يرون أن الدور الحالي للإرشاد

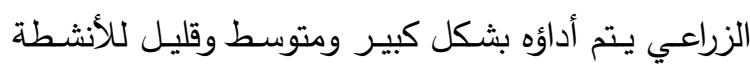
المتعلقة بمجال الدراسة الإرشاد التسويقي. ط. أن المهندسين الزراعيين يرون أن الدور المستقبلي للإرشاد

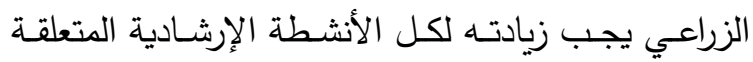

$$
\text { بالإرشاد الزراعي التسويقي. }
$$

ومن هنا فإن الدراسة ترى ضرورة وضع الخطة المقترحة

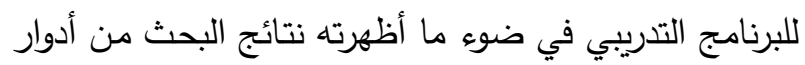

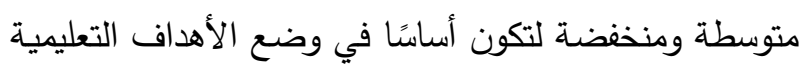
الإرشادية.

\section{r. تحديد وتثخيص المشكلة:}

بناء على المؤشرات سالفة الذكر للمهندسين الزراعيين فإن

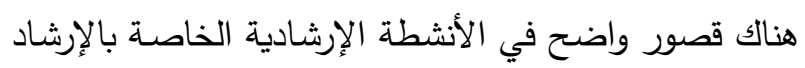

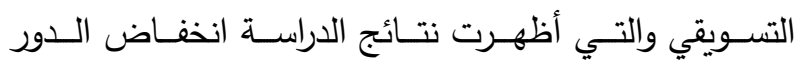

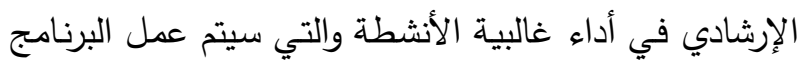
التدريبى المقترح من أجلها ويرجع ذلك إلى الئ:

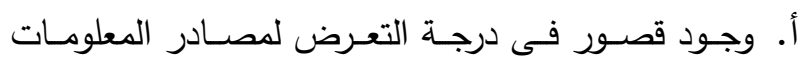
الزراعية الخاصة بالإرشاد التسويقي.

ب.قلة عدد الدورات التتريبية الخاصة بالإرشاد التسويقي. ج. انخفـاض شـديد فـى الخـدمات الإرشـادية التسى يقدمها المهندون الزراعيون لمزارعي منطفة الدراسة.
خطـة عمـل البرنـامج التـدريبي لتعـديل البنيـان المعرفي

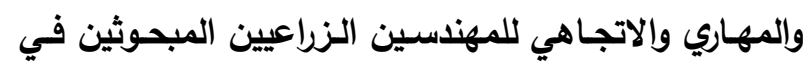
مجال الإرشاد التسويقي. تم وضع مقترح لخطة عمل إرشادية لبرنامج تدريبي يوجها

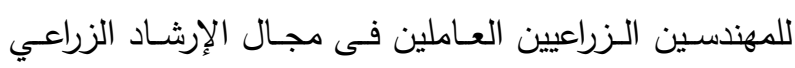

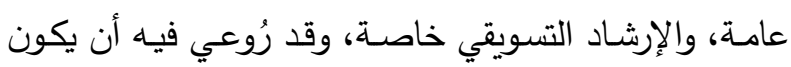

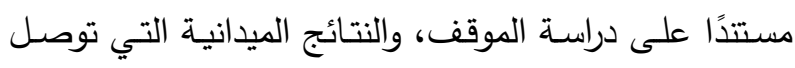
إليها هذا البحث. ويمكن تحديد خطوات إعداد البرنامج التدريبي المقترح في

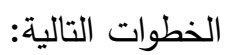

\section{1. تحديد مؤشرات الاحتياجات التدريبية:}

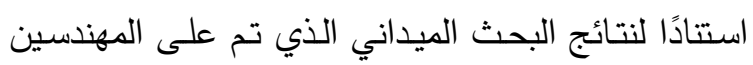

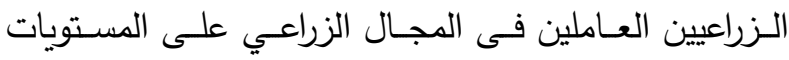
المحلية بالقرى، وقد تم تحديد المؤشرات التالية للاحتياجات

$$
\text { التدريبية والتي تتلخص فيما يلي: }
$$

أ. انخفـاض متوسـط أعمـار غالبيـة المهندسين الـزراعيين

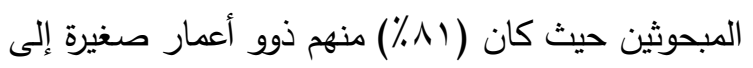

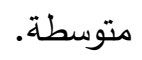

ب. مـا يزيــــــن نصـف المهندسين الزراعيين المبحوثين

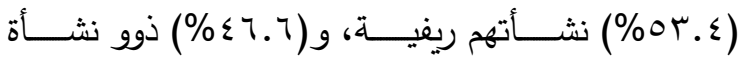

$$
\text { حضرية. }
$$

ج. ارتفـاع المستوى التعليهـي لغالبيـة المهندسين الزراعيين المبحوثيين حيث كان (؟.4^\%) منهم ذوو مؤهلات عليا

$$
\text { ومؤهلات متوسطة. }
$$

د. انخفــاض عــد ســوات عمـل المهندسـين الـزراعيين

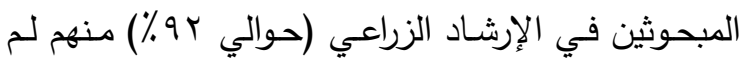
تزد خبرتهم فيه عن سبع سنوات.

هـ انخفـــاض خبــرة المهندســين الــزراعيين الزراعيــة

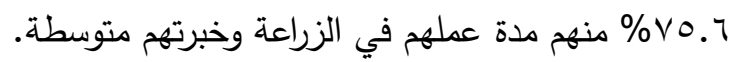


الإطـار الزمنـي للبرنـامج: يقترح تحديد أسبوع لكل مستوى تدريبي ويزيد وفقًا للحاجة.

ثالثاً: أهم المشكلات التي تواجه المهندين الزراعيين المبحوثين والتي تقف حجر عثرة في سبيل تحقيق الأهداف المتعلقة بأنشطة مجال الدراسة: تعد المشكلات مرآة حقيقية تتنبأ بالعديد من الحقائق التي تعوق العملية التتموية من ضعف وسوء فى التخطيط والتتفيذ، وغالبًا ما يُواجه القائمون بالأنشطة التموية بصفة عامة

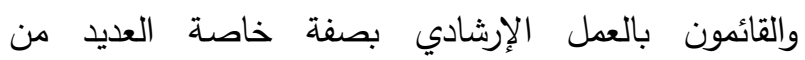

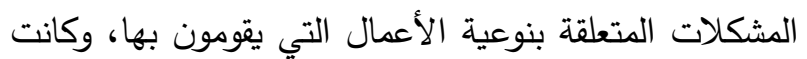
أهم المشكلات التي واجهت العمل الإرشادي الزراعي فى تلك لك الدراسة من وجهة نظر المهندسين الزراعيين المبحوثين، والتي تعوق أداءهم في العمل الإرشادي بمنطقة الدراسة فى ظل سياسة التحرر الاقتصادي كما يلي: ا ـ مشكلات مرتبطة بالعمل الزراعي. r. مشكلات تواجه العمل الإرشادي. r. مشكلات تتعلق بالموارد البشرية الإششادية. ع. ـ مشكلات تتعلق بالموارد المادية.

๑. مشكلات تتعلق بالرضا الوظيفي للمهندسين الزراعيين. يوضح الجدول(V) توزيع المهندسين المبحوثين وفقًا لأهم المشكلات التي تعترضهم للنهوض ببعض المجالات الإرشادية المستحدثة فى ظل سياسة التحرر الاقتصادي من لهن وجهة نظر المهندسين المبحوثين كما يلي: أولًا: مشكلات تواجه العمل الزراعى:

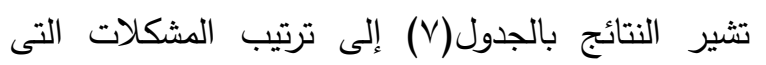
تواجه المهندسين المبحوثين والمرتبة تتازليًا وفقًا لعدد الذين ذكروها وهي: - نواهي - ارتفاع تكلفة الانتاج الزراعي 9. - الاعتماد عاي الأساليب التقليدية في الزراعة اب٪٪.
د. نــدرة المتخصصـين فـى الإرشــاد التسـويقي مسن بـين المهندسـين الـزراعيين المبحـوثين العـاملين فـي مجـال

$$
\text { الإرشاد الزراعي. }
$$

\section{r. الأهداف التعليمية للبرنامج التدريبى:}

تم صياغة الأهداف التعليمية لهذا البرنامج التدريبي في شكل ما سوف يتم إضـافته من معارف للمتدرب بعد الانتهاء

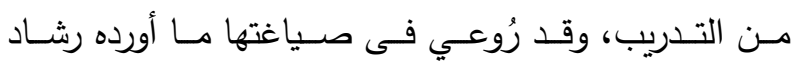

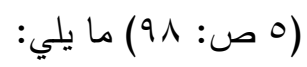
أ. التغير السلوكي المراد إحداثه (تغير معرفي). ب. الفئسة أو الجمهـور المـراد تدريبـه (المهندسـون الزراعيـون العاملون فى مجال الإرشاد وخاصة الإرشاد التسويقي).

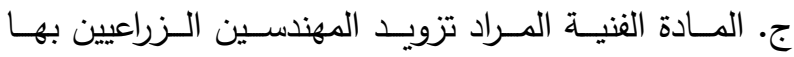
(المجالات الخاصة بالتسويق، وخاصة تلك الأنشطة التي

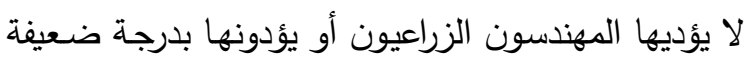
أو متوسطة). د. المنطقة المراد إحداث التغير بها (منطقة الدراسة). צ - تصميم مقترح لخطة عمل البرنامج. استتادًا على الأهداف السـابق تحديدها فقد تم تصـميم خطـة العمل لهذا البرنـامج التدريبى وقد رُوعي فيه الإجابـة على كل الأسئلة المتعلقة بنوعية أو ماهية النشاط التعليمى

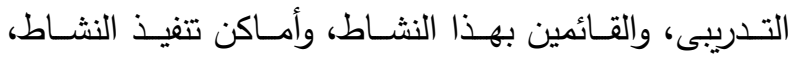
ومواعيده، والطرق التعليمية، أيضا كيفية تتفيذ النشاط، وأخيرًا أسلوب تقويم النشاط كما هو موضح بالجدول (T). يقترح لقياس التقدم الحادث للى المهندسين الزراعيين في بنيانهم المعرفي والمهاري والاتجاهي ما يلي: ا ـ عمل استقصــاء للمهندسـين قبـل وبعـــ انتهـاء البرنـامج التدريبي. r. سؤال الرؤساء عن مدى التقدم للمهندسين المشاركين في

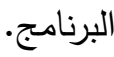
r. عمل دراسة بعد انتهاء البرنامج للتعرف على آثاره. 
جدول 7 . خطة عمل لبرنامج تدربي لتطوير البنيان المعرفي والمهاري والوجداني في مجال الإشـاد التسويقي لدى المرشدين

الزراعيين

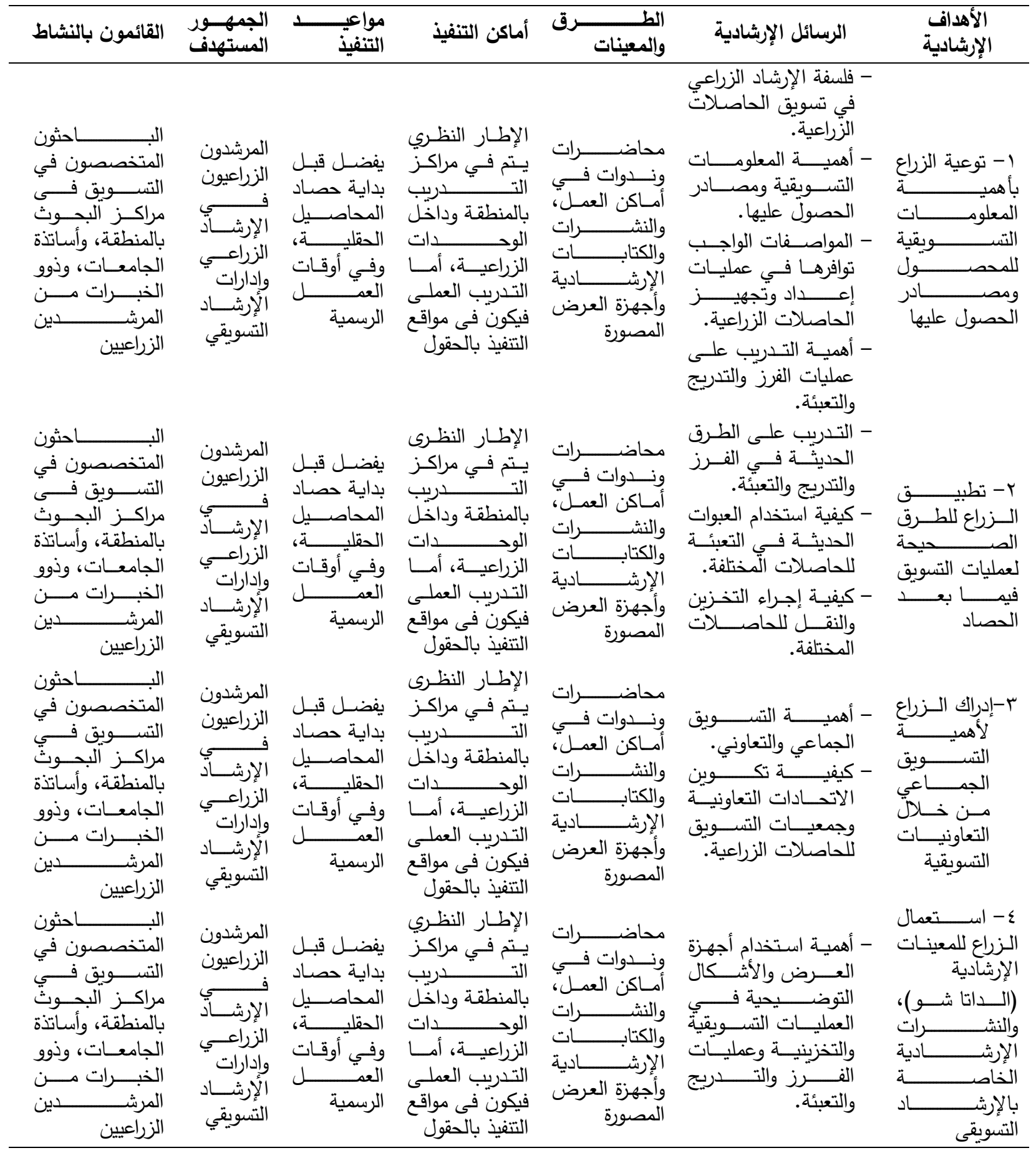


جدول v. توزيع المبحوثين وفقًا لأهم المشكلات التي تواجههم في الإرشاد التسويقي في ظل العولمة

\begin{tabular}{|c|c|c|c|c|}
\hline الترتيب & الداختيب & $\%$ & 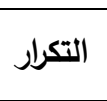 & المشكلات مرتبة تنازليًا \\
\hline & & & & أولًا: مشكلات تواجه العمل الزراعي \\
\hline$\checkmark$ & r & $r \cdot . r$ & vo & ضعف دور الجمعيات الزراعية في توفير مستلزمات الإنتاج \\
\hline 7 & r & r... & $\vee \wedge$ & الاعتماد على الأساليب التقليدية في الزراعة \\
\hline r & 1 & $r v . q$ & $1 \cdot \varepsilon$ & ارتفاع تكلفة الإنتاج الزراعي \\
\hline$\wedge$ & $\varepsilon$ & IV.V & 74 & غياب دور الجمعيات الزراعية فى عملية التسويق \\
\hline \multirow[t]{3}{*}{1.} & $\circ$ & IT.r & $\varepsilon 9$ & عدم الالتزام بالتوصيات الفنية \\
\hline & & $1 \ldots$ & rVt & مجموع التكرارات \\
\hline & & & & ثانيًا: مشكلات تواجه العمل الإرشادي \\
\hline 17 & ○ & 10.1 & rV & عدم وجود نشرات سعرية دورية \\
\hline r & r & r..^ & rq & عدم كفاية النشرات والملصقات الإرشادية \\
\hline ir & r & r.r.r & $\varepsilon$. & ضعف الاهتمام بمشاركة القيادات الريفية في عملية التتمية \\
\hline 11 & 1 & $r \varepsilon$. & $\varepsilon r$ & عدم مناسبة البرامج الإرشادية لتلبية احتياجات الشباب الريفي \\
\hline \multirow[t]{3}{*}{10} & $\varepsilon$ & 17.1 & r. & ضعف التعاون بين الجهاز الإرشادي والمؤسسات الخدمية الَّخرى \\
\hline & & $1 \ldots$ & 189 & مجموع التكرارات \\
\hline & & & & ثالثًا: مشكلات خاصة بالموارد البشرية الإرشادية \\
\hline 9 & 1 & Or.r & rt & عدم وجود أعداد كافية من المهندسين المتخصصين \\
\hline iv & r & $19 . r$ & r & انخفاض كفاءة بعض المهندسين وقلة خبرتهح \\
\hline \multirow[t]{3}{*}{$1 \varepsilon$} & r & YA.r & $r \varepsilon$ & إقحام المهندسين في الإعمال الإدارية \\
\hline & & $1 \ldots$ & ir. & مجموع التكرارات \\
\hline & & & & رابعًا: مثكلات خاصة بالموارد المادية الإرشادية \\
\hline 0 & r & $r v . \wedge$ & $\Lambda \vee$ & عدم توافر وسائل المواصلات اللازمة للعمل \\
\hline 1. & r & Y.r & $\varepsilon 9$ & عدم توافر المعينات والأجهزة اللازمة للتدريب ولاتصال الإرشادي \\
\hline \multirow[t]{3}{*}{$\varepsilon$} & 1 & $\varepsilon \cdot .9$ & $9 \varepsilon$ & قلة الاعتمادات المالية اللازمة للعمل \\
\hline & & $1 \ldots$ & r. & 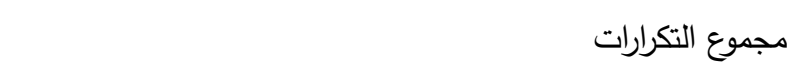 \\
\hline & & & & خامسًا: مشكلات خاصة بالرضا الوظيفي \\
\hline 1 & 1 & $01 . V$ & 1.7 & ضآلة المرتبات وعدم مناسبتها لطبيعة العمل \\
\hline \multirow[t]{3}{*}{ r } & r & $\varepsilon \wedge . r$ & 99 & قل الة الحوافز والأجور الإضافية \\
\hline & & $1 \ldots$ & r.o & 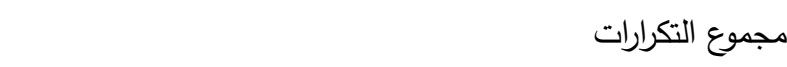 \\
\hline & & & $11 \cdot 7$ & المجموع العام للتكرارات \\
\hline
\end{tabular}

المصدر : جُمعت وحُسبت من استمارة الاستبيان.

- ضعف دور الجمعيات الزراعية فى توفير مستلزمات - عدم الالتزام بالتوصيات الفنية لزراعة المحاصيل $\%$ \%r.r 


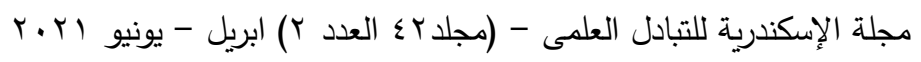

أشارت النتائج بالجدول إلى ترتيب المشكلات التي تواجه المهندسين المبحوثين والمرتبة تتازليًا وفقًا لعدد الذين ذكروهم

- ضآلة المرتبات وعدم مناسبتها لطبيعة العمل V.

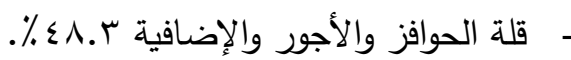

\section{المراجع}

أبو حطب، رضـا عبد الخالق، وآخرون (دكتور)، " دراسة تحليلية لبعض متغيرات الإرشاد التسويقي الزراعي بمحاصيل الفاكهة وضدية

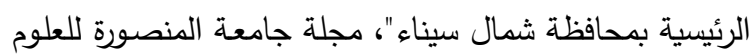

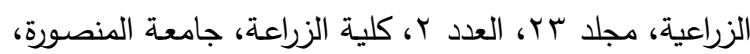
. 991 الإدارة المركزيسـة للإرشــاد الزراعـي بــوزارة الزراعــة واستصــلاح

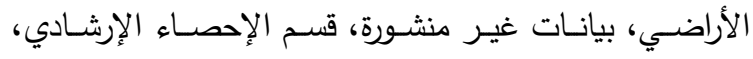

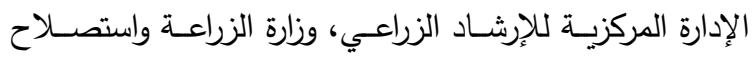

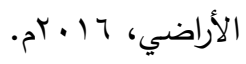

جمعـه، يوسـف أحمـد، إدراك المرشـدين الـزراعيين لـدور الإرشـاد

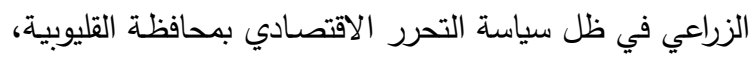

رسالة ماجستير، كلية الزراعة، جامعة بنها، 10 • بم. رشـاد، سعيد عباس محمد (دكتور)، محاضـرات غير منشورة في

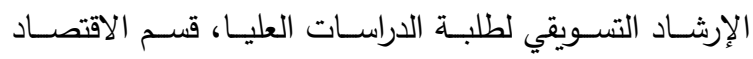

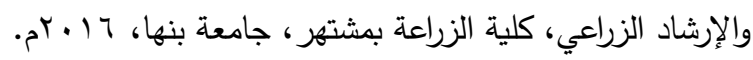
رشاد، سعيد عباس، الهوش، مصباح سالم (دكتوران)، نحو رؤيسة

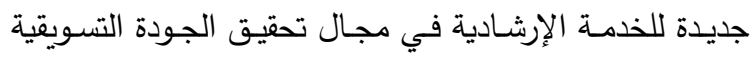

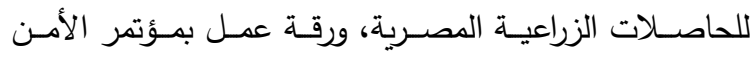
الغذائي والزراعـة المستدامة في ظل التغيرات المناخية -كلية الزراعة، جامعة جرش، الأردن، 9 1 • بَم. ريحان، محمد كامل (دكتور)، "مدخل لدراسات التسويق للمنتجات

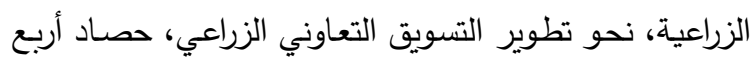

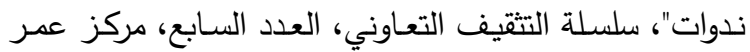

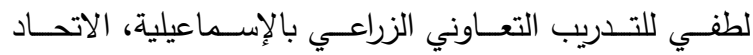

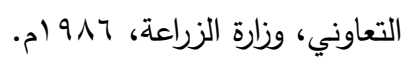

ثانيًا: مشكلات تواجه العمل الإرشادي الداعم للإرشاد التصديري: - (الت

أوضـــت النتـائج بالجدول إلى ترتيب المشكلات التى

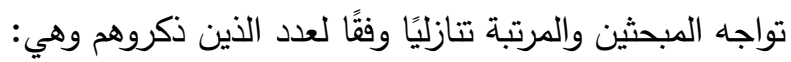
- عدم مناسبة البرامج الارشـادية لتلبية احتياجـات الشباب

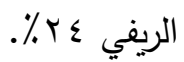

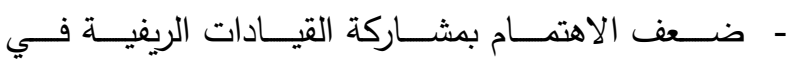

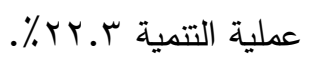
- عدم كفاية النشرات والملصقات الارشادية ^ـــץ\%. - - ضعف التعاون بين الجهاز الارشادي والمؤسسات

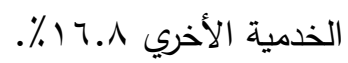
- عدم وجود نشرات سعرية دورية 10.1\% ثالثًا: مشكلات خاصة بالموارد البشريـة الإرشادية: أظهرت النتائج بالجدول إلى ترتيب المشكلات التي تواجه

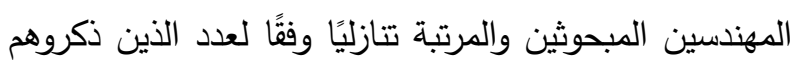
وهي:

- عدم وجود أعداد كافية من المهندسين المتخصصين \% or.o

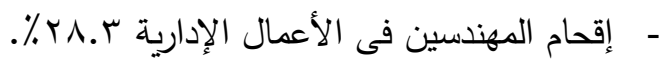
- انخفاض كفاءة بعض المهندسين وقلة خبرتهم ب.9 1\%. رابعًا: مشكلات خاصة بالموارد المادية الإرشادية: أشارت النتائج بالجدول إلى ترتيب المشكلات التى تواجه المهندسين المبحوثين والمرتبة تتازليًا وفقًا لعدد الذين ذكرهم وهي: - قلة الاعتمادات المالية اللازمة للعمل 9 . . ٪٪.

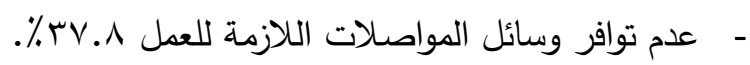
- عدم توافر المعينات والأجهزة اللازمة للتدريب والاتصال الإرشادى r.r.

خامسًا: مشكلات تتعلق بالرضا الوظيفي للمهندسين: 
مصـطفى، أحمــــــيد، (دكتـور )، تحـديات العولمــة والتخطـيط

الاستراتيجي - رؤيسة مدير القـرن الحسادي والعشـين، الطبعـة

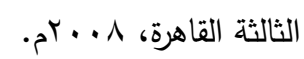

John p . Donetsk. psychology, second Edition, west publishing Combany, new York, U.S.A., 1985.

Swanson B.. E., Clear, H. B., In Swanson, B. E., The Agricultural Extension. A reference manual Second Editor, F.A.O., Rome , 1990
علام، سعد طه، التحرر الاقتصـادي والخصخصـة في الاقتصـاد المصري، معهد التخطيط القومي، مذكرة داخلية رقم (ع ـ 9)،

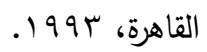

محروس، فوزي نعيم، ووهبة، أحمد جمال (دكتوران)، دور الإرشاد

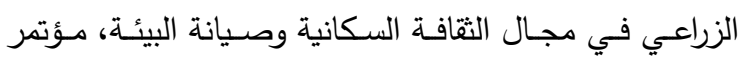
استراتيجية العمل الإرشادي التعاوني في ظل سياسة التحرر

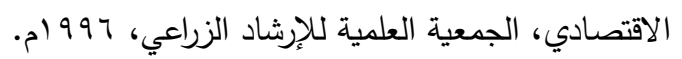




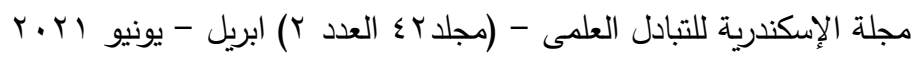

ABSTRACT

\title{
Agricultural Engineers' Awareness of the Role of Agricultural Marketing Extension under Globalization in Qalyubia Governorate
}

\author{
Saied Abbas Mohamed Rashad, Mosbah Salem AL-Hosh, Reda Tahawy Taher Tahawy
}

The research mainly aimed at determining the level of awareness of the current and future role of agricultural extension in the field of marketing guidance under the policy of economic liberalization (globalization) from the viewpoint of agricultural engineers in Qalyubia Governorate, by achieving the following sub-objectives:

1- Determining the extent of agricultural engineers' awareness of the current and future role of agricultural extension in the field of marketing extension.

2- Knowing the views of agricultural engineers regarding the advancement of their tasks in the field of marketing guidance regarding: The most appropriate dates for them for training, the location of the training courses, their preferred methods of training, and the trainers in charge of the training.

3- Proposing an action plan for a training program for the development of marketing guidance under globalization or economic liberalization from the viewpoint of agricultural engineers according to their personal, communicative, social characteristics, and their level of awareness of the marketing advisory role.

To achieve these goals, a questionnaire form was designed that was collected in a personal interview with a sample of 121 respondents from agricultural engineers (specialists, technicians) in Qalyubia Governorate, and the frequencies, numbers, percentages, and averages were used to display the data and arrange the tasks specific to the role performed by agricultural engineers, in the field of marketing counseling.

The most important results are as follows:

1- More than two-thirds of the respondents had a low or medium vision of the current advisory role, indicating the severe relative decline in the performance of the workers in the extension services.
2- The arrangement of extension activities according to the weighted average of the current role of agricultural extension in the field of consumption and marketing of agricultural crops from the viewpoint of agronomists, was arranged as follows: "The farmers' application of correct practices when transporting the crop according to its nature" in the first order with a weighted average of $(50,3)$. The degree of "farmers' use of indicative aids (data show) and advisory bulletins for marketing and extension in the last rank with a weighted average of (33.3) degrees, and the rest of the extension activities ranked from the second to the fifth.

3- The division of the current role in the field of marketing and consumption of agricultural crops into three categories according to the degree of performance of the respondents for this role, the results indicated that the low performance was limited to (33.3 - 40.3) degrees, and the average performance was limited to (40.3 - 47.3) degrees, and the high performance, which reached (47.3) degrees or more.

4- A proposal for an indicative action plan for a training program has been drawn up for agricultural engineers working in the field of agricultural extension in general, and marketing guidance, and it has been considered that it be based on the study of the situation and the field results reached by this research.

5- The most important problems that the surveyed agricultural engineers faced, which hinder their performance in the extension work in the study area under the economic liberalization policy, were as follows: problems related to agricultural work, problems facing extension work, problems related to extension human resources, problems related to material resources, problems related to job satisfaction for agronomists. 